\title{
TRANSFORMACIONES AGRARIAS EN EL CAMPO VALENCIANO DURANTE LA EDAD MODERNA. EL CASO DE LA COMARCA DE ALCOI (SS. XV-XVIII)
}

\author{
LLUÍS TORRÓ GIL \\ Universitat d'Alacant ${ }^{\mathrm{a}}$
}

\begin{abstract}
RESUMEN
La presente investigación muestra un caso local en el que las transformaciones agrícolas a lo largo de la Edad Moderna tuvieron un gran alcance. Alrededor del núcleo protoindustrial de Alcoi se produjo un intenso proceso de sustitución de cultivos que alteró la fisonomía de las actividades rurales de una zona tradicionalmente conceptuada como pobre desde el punto de vista agrario. El catálogo de estos cambios es sustancial: la sustitución de la cebada por el trigo, la introducción temprana del maíz y su fuerte difusión, el avance del cultivo de la vid y, finalmente, la adopción de rotaciones de cultivos en el regadío, que conoció una extensión modesta, pero significativa para un área montañosa. A lo largo del texto se describen y tratan de ser explicados estos cambios, teniendo en cuenta el marco protoindustrial en el que se inscriben, así como su contextualización en el ámbito valenciano y español.
\end{abstract}

Palabras clave: agricultura, cambio agrario, Edad Moderna, País Valenciano, protoindustria, cereal

\section{ABSTRACT}

This article examines a case study of profound agricultural transformations along the Early Modern Age. Around the protoindustrial town of Alcoi there was

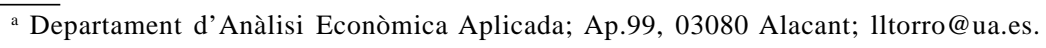


an intense process of substitution of cultivations that altered the physiognomy of the rural activities of an area traditionally considered as poor from the agrarian point of view. The catalogue of these changes is substantial: the substitution of wheat for barley, the early introduction of corn and its strong spread, the advance of the cultivation of vine, and, finally, the adoption of crop rotations in the irrigable area that was part of a limited extension of land, though significant for a mountainous area. Throughout the text these changes are described and explained, keeping in mind the proto-industrial framework in which they appear, as well as their context in the Valencian and Spanish environment.

Keywords: agriculture, agrarian change, Early Modern Age, Valencia Country, protoindustry, cereal

JEL Classification: N53, N93, O13, O18, Q10, Q56

Las investigaciones sobre la agricultura valenciana en la Edad Moderna se han multiplicado en los últimos veinte años. Esto ha permitido dibujar un panorama bastante completo y definido, a pesar de las aún numerosas lagunas historiográficas ${ }^{1}$. Para la práctica totalidad de los autores que se han aproximado a ella, la realidad agraria valenciana a lo largo del período que vamos a considerar podría definirse como un mundo en lenta pero permanente transformación. Aunque esta afirmación parezca una tautología, se ha construido contra una imagen inmovilista que ha predominado durante mucho tiempo. El «progreso» agrario se identifica, ahora, con una creciente orientación comercial de la producción. En este marco, se tiende a distinguir una agricultura rica y comercial en las comarcas litorales de regadío, frente a un mundo agrícola atrasado en las comarcas del interior en las que predominaba el secano. Las destacadas realizaciones de los extensos regadíos costeros han provocado que la mayor parte de las investigaciones se haya dedicado a ellos de forma casi exclusiva².

Con todo, en los últimos tiempos algunos historiadores han empezado a darse cuenta de las limitaciones de esta imagen ${ }^{3}$, y ello por dos razones. En primer lugar, porque la identificación entre regadío y agricultura comercial es precipitada. De

\footnotetext{
${ }^{1}$ Véanse Ardit (1993) o Peris (1995).

${ }^{2}$ Una buena muestra de lo que estoy señalando se puede encontrar en el trabajo de Peris (1995).

${ }^{3}$ Cabe destacar en este sentido la contribución de Manuel Ardit (1996, p. 69), en la que señala que «[...] a pesar del tópico no se puede identificar agricultura desarrollada con agricultura de regadío. Al contrario, las producciones de subsistencia solían cultivarse en regadío, donde se obtenían mayores rendimientos. Dejando aparte los secanos interiores dedicados al cultivo del cereal en rotación bienal o incluso alternancias más largas, la tierra no regada del País Valenciano estaba intensamente capitalizada y se dedicaba fundamentalmente a los cultivos arbustivos y arbóreos. Éstos, que eran básicamente la viña, el olivo y el algarrobo, tenían como destino el mercado».
} 
hecho, uno de los principales cultivos comerciales valencianos -tanto por su extensión como por su valor-, la viña, era básicamente de secano, y sólo excepcionalmente se encontraba en zonas irrigadas ${ }^{4}$. Aparte de albergar algunos cultivos que no se podían desarrollar en ninguna otra parte -como el arroz o las hortalizas-, o que no resultaban rentables -como la morera-, el regadío producía, fundamentalmente, bienes de subsistencia: cereales y leguminosas. En segundo lugar, porque, además, reducir el ámbito regado a las comarcas costeras es exagerado: los regadíos de las zonas de interior -pese a sus modestas dimensiones- representaban una parte que no debe ser menospreciada, generando, en muchos lugares, una proporción considerable -y a veces incluso mayoritaria- del valor agrario.

La villa de Alcoi, protagonista desde el siglo XVIII de uno de los más notables ejemplos locales de industrialización en el ámbito español, se convirtió, a lo largo del período que aquí consideramos, en el eje de un espacio económico articulado alrededor de la producción textil lanera. La zona se caracteriza por encontrarse en un ámbito geográfico montañoso surcado de valles ${ }^{5}$. Desde el punto de vista climático y edafológico se han de distinguir los valles de orientación SO-NE -entre los que destaca la amplia hoya formada por el río Serpis o Alcoi, situada en el centro de la comarca-, de suelos más fértiles y pluviometría relativamente elevada-500-600 mm de media anual-, de la Foia de Castalla, situada al oeste y separada del resto por las sierras de Mariola y el Menejador, más fría, menos húmeda -menos de 400 mm-y de suelos más pobres. Históricamente, la zona occidental se caracteriza por un hábitat concentrado en villas - con una dispersión subsiguiente en forma de grandes unidades de producción, llamadas masos-, mientras que la zona oriental, fragmentada en pequeños valles y en la que predominó la población morisca hasta 1609, se caracteriza por un poblamiento más disperso en pequeños núcleos. Alcoi, justamente, se encuentra a caballo de estas dos áreas, compartiendo características físicas de ambas. En general, la abrupta orografía se compensa con la posibilidad de extender algunos regadíos, muy condicionados, no obstante, por el escaso de caudal de los ríos y la irregularidad de las precipitaciones -con un verano muy seco. Entre el secano predominante aparecen, de este modo, pequeños espacios irrigados que merecieron encendidos elogios de viajeros expertos a fines del XVIII ${ }^{6}$. A pesar de su

${ }^{4}$ Según las estimaciones de Tomás Ricord, supondría un 14,5 por cien del valor agregado a finales del s. XVIII, siendo superado únicamente por la producción cerealícola: vid. Peris (1995, p. 495). Cabe señalar, no obstante, algunas excepciones en las que la viña era cultivada en parcelas irrigadas. El caso más relevante es el de Alacant, donde el predominio de este cultivo en la huerta era casi absoluto. Vid. Alberola (1984, pp. 215-218).

${ }^{5}$ Nebot (1993).

${ }^{6}$ No hay más que leer las admirativas descripciones de Cavanilles, entre las que, sin duda, destaca la de Alcoi, de la que señala que es «[...] una de las mejores vistas del reyno [...], sumamente vistosa por la multitud de huertas en anfiteatro, y variedad de tintes en los árboles y producciones [...] [En la parte oriental del término] nada queda inculto, todo es huerta, todo respira lozanía, fertilidad y abundancia por las muchas aguas que fecundan el suelo desde las colinas hasta las riberas del río, que corre por lo profundo de la hoya.» Cavanilles (1795-97, II, pp. 192-193). 
proximidad al mar, la zona se encuentra aislada del mismo por las barreras montañosas -con cimas que se sitúan entre los 1.200 y 1.500 m de altitud-, lo cual le confiere al clima una marcada tendencia hacia la continentalidad y provoca fuertes dificultades de comunicación.

La especialización industrial de la zona ha sido atribuida a la pobreza agrícola propia de las áreas montañosas? ${ }^{7}$. No obstante, las descripciones de los ilustrados de fines del XVIII contradicen ampliamente esta imagen y, de hecho, la agricultura de la zona -y la de la propia villa de Alcoi, en particular- era la segunda de la provincia de Alacant en cuanto al valor de su producción a mediados del XIX ${ }^{8}$. Las transformaciones agrarias, pues, parecen haber contribuido de forma decisiva al éxito en el proceso de industrialización alcoyano, tanto desde el punto de vista de la liberación de mano de obra necesaria para sostener el auge del sector secundario, como desde el de haber facilitado la existencia de una oferta suficiente de alimentos para una población que mantuvo unas notables tasas de crecimiento, incluso en el relativamente excepcional contexto valenciano -especialmente durante el siglo XVIII ${ }^{9}$. A su vez, estos factores pueden leerse en sentido inverso, es decir, el desarrollo manufacturero también sería un factor de los cambios agrarios ${ }^{10}$. El creciente grado de comercialización de la agricultura comarcal fue, por lo tanto, una condición crucial en este proceso. La presente contribución pretende, precisamente, acercarse a la caracterización de dichos cambios.

Por otro lado, creo que la orientación comercial de la agricultura, entendida normalmente como el objetivo final del «desarrollo», debe concebirse, en primera instancia, como un signo de profundas transformaciones en la organización de la producción ${ }^{11}$. Es, básicamente, el resultado de un proceso que tiende a separar a

\footnotetext{
${ }^{7}$ Véase Aracil y Garcia Bonafé (1974). La propia teoría de la protoindustrialización en su formulación original (Mendels, 1972) presuponía una agricultura pobre -normalmente en zonas montañosas- como punto de partida y una agricultura desarrollada, en la misma región, como garantía del éxito en el tránsito hacia la mecanización. Una formulación más rigurosa y compleja de esta cuestión -aunque sin rebasar los límites del planteamiento de Mendels-puede verse en Kriedte, Medick y Schlumbohm (1986, pp. 29-47). Sin embargo, como ya demostró en su momento Gay Gullickson (1983), este determinismo parece excesivo: una agricultura comercial no tiene por qué convertirse en un impedimento para el desarrollo manufacturero, siendo los factores determinantes la estacionalidad de la producción agraria y la distribución de la propiedad de la tierra.

${ }^{8}$ Archivo Histórico Provincial de Alacant: Censo provisional de riqueza de la Provincia de Alicante, 1857. Debo esta referencia a la amabilidad de Pedro Díaz.

9 Torró Gil (2000, pp. 69-70).

${ }^{10}$ No se trata, pues, de repetir esquemas mecanicistas que atribuyen en exclusiva a la dinámica del sector agrario toda la responsabilidad en el crecimiento o el atraso industrial. Los procesos históricos no deben leerse en un sentido unidireccional puesto que, aunque fragmentemos el análisis, el objeto último de estudio es la totalidad social, y cualquier factor que provoque cambios se ha de ver, a su vez, inevitablemente alterado por los mismos.

${ }^{11}$ Este trabajo tiene una profunda deuda intelectual con el trabajo de Maurice Aymard (1983). Asimismo, para un análisis sobre un mercado comarcal de la Cataluña intermedia que se inspira en parte en la contribución de Aymard, v. Tello (1995, pp. 372-431).
} 
los productores directos de las condiciones objetivas de la producción, provocando una concentración de la riqueza y, fundamentalmente, de la propiedad de la tierra. Con ello, el trabajo se subsume progresivamente -y de formas muy diversas- en un proceso que ya no tendrá como finalidad primordial la reproducción social y material de los propios productores. Rastrear las huellas de las sustituciones de cultivos y técnicas no es, visto desde esta perspectiva, una forma de medir el grado de desarrollo agrario ${ }^{12}$, sino la mejor forma de acercarse a la facies del proceso apuntado. El caso estudiado ejemplifica cómo el conocimiento de las modificaciones en las formas de conducir la tierra y en los patrones de subsistencia puede ayudarnos a entender sus características específicas, las limitaciones que imponían los medios natural y social, y las vías para adaptarse a ellas y, llegado el caso, transgredirlas ${ }^{13}$.

\section{LOS CEREALES: EL DESPLAZAMIENTO DE LA CEBADA POR EL TRIGO Y LA ADOPCIÓN DEL MAÍZ}

La saludable insistencia de los especialistas en la gran diversificación que alcanzó la agricultura valenciana a finales del siglo XVIII no debe hacernos olvidar un rasgo fundamental: el predominio de los cereales. Bajo la forma de cebada, trigo, maíz o arroz, constituían la base de la alimentación humana. Según la estimación de Tomás Ricord, en 1791 suponían el 43,4 por cien del valor agregado total de la agricultura valenciana ${ }^{14}$. Deberíamos, pues, empezar por aquí. Es evidente que, si pudiésemos establecer una comparación entre las estimaciones de Ricord y otras similares para los siglos XV o XVI, o incluso para el XVII, veríamos casi con toda seguridad que la proporción que representaban los cereales en el conjunto del valor agrario se habría reducido de forma significativa. Con todo, hay que hacer dos objeciones a esta rápida y, hasta cierto punto, contundente

${ }^{12}$ No es ocioso recordar que este concepto introduce elementos valorativos en el análisis, que han de ser utilizados con mucha cautela. Para una crítica de este concepto desde diversas perspectivas v. Rist (1996).

${ }^{13}$ Aún es demasiado frecuente en la historiografía valenciana y española -y particularmente la referida a la Edad Moderna- la descripción de la agricultura de un determinado espacio geográfico en términos estáticos, como si la estructura de los cultivos hubiese sufrido escasas variaciones a lo largo de los siglos. Este punto de vista, que se adopta normalmente de forma inconsciente, hace que no se acaben de captar adecuadamente todas las implicaciones que tienen estos cambios.

${ }^{14}$ La estimación incluye también el valor de las legumbres. Ahora bien, en términos físicos -cantidad de hectolitros-, estas sólo constituyen el 3,8 por cien del total, excluyendo el arroz. Dado su escaso valor, la participación en las cifras citadas en el texto sería absolutamente menospreciable. Los cálculos se han hecho sobre la base de las cifras que ofrece Peris (1995, p. 487). 
observación: para empezar, la reducción relativa del valor no tendría probablemente correlato con la de la superficie, y, en segundo lugar, los cereales continuaban predominando en el campo valenciano en la segunda mitad del siglo XIX ${ }^{15}$.

Esto no debe interpretarse como un signo de atraso. El mantenimiento de los cereales, visto de este modo, constituye, en la práctica, una falsa pista. Y también lo puede ser la reducción de su proporción en el conjunto agrario si no la contextualizamos. Al respecto, quisiera llamar la atención sobre una cuestión que, a pesar de haber sido destacada por los historiadores, desde mi punto de vista no se ha valorado adecuadamente: el ascenso del maíz al segundo lugar en el ranking de los cereales. Este cambio es, sin duda, el más llamativo, y tiene su reverso en otro que, hasta donde alcanzan mis conocimientos, ha pasado desapercibido: la reducción de la cebada al papel de cereal secundario ${ }^{16}$. En plena Edad Media, la cebada, cultivo mediterráneo por excelencia ${ }^{17}$, era el cereal predominante, probablemente doblando al trigo en términos físicos durante el siglo XIII ${ }^{18}$. En cambio, 450 años más tarde, como se puede ver en el Cuadro 1, el trigo se ha transformado en el cereal dominante, con dos tercios del total, mientras que la cebada, aunque conserve aún una presencia significativa, se ha visto relegada al tercer lugar, desplazada por el maíz, con un modesto 12 por cien $^{19}$. Cómo se produjo este proceso y qué implicaciones técnicas y sociales tuvo, serán las cuestiones que servirán de hilo conductor de la primera parte del trabajo.

Lo primero que hay que determinar son las dimensiones y la cronología de este proceso de sustitución para el caso que nos ocupa. Como en el resto del país, en Alcoi y su comarca la cebada sería el cereal predominante, en condiciones de igualdad con el trigo, a lo largo del siglo XV. Según Antonio J. Mira (1996, pp. 248), «[...] el trigo y la cebada suponían en todos los casos un mínimo de entre dos tercios y tres cuartos del producto agrícola total». Las recaudaciones en especie del monopolio de los molinos demuestran, por un lado, que en este período la cebada se destinaba fundamentalmente al consumo humano, y, por otro, que la

\footnotetext{
${ }^{15}$ Garrabou (1985, pp. 24-32).

${ }^{16}$ Puede resultar útil la comparación con una realidad bien distinta, la de las tierras castellanas de Segovia: allí la cebada perdió peso durante el siglo XVII, especialmente frente al centeno -seguramente para alimentar a la ganadería estante-, para volver a ganar terreno a lo largo del XVIII (García Sanz, 1986, pp. 94-142).

${ }^{17}$ Le Roy Ladurie (1969, p. 53). Sobre la tipología y las características de los diferentes cereales, desde un punto de vista histórico, v. Comet (1992).

${ }^{18}$ Véase Torró Abad (1999, p. 149). Más adelante, la cebada se mantendría en términos de igualdad con el trigo, incluso en regadíos como Sueca: vid. Furió (1982, pp. 74-75).

${ }^{19}$ Hay que tener en cuenta, además, que en determinadas comarcas -como el Alacantí descrito por Cavanilles (1795-97, II, p. 251)- se produjo una especialización en la producción de cebada, con lo cual el proceso se ve magnificado para el resto. Las proporciones reflejadas en el gráfico, con todo, serían seguramente menores, ya que no se cuantifica la producción de arroz. Sobre el progreso del cultivo de este cereal, v. Mateu (1987) y Peris (2003, pp. 96-114).
} 


\section{CUADRO 1}

PRODUCCIÓN DE CEREALES (ESPECIE), PAÍS VALENCIANO, 1791

\begin{tabular}{|l|c|c|}
\hline & Fanegas castellanas & Porcentaje \\
\hline Trigo & 1.781 .346 & 65,64 \\
\hline Maíz & 504.622 & 18,59 \\
\hline Cebada & 325.766 & 12,01 \\
\hline Avena & 54.831 & 2,02 \\
\hline Centeno & 47.232 & 1,74 \\
\hline
\end{tabular}

Fuente: Anes (1970, pp. 148)

CUADRO 2

RECAUDACIÓN EN ESPECIE DE CEREALES (PORCENTAJES). TERCIO DIEZMO DE ALCOI Y PENÀGUILA, C. 1600

\begin{tabular}{|l|c|c|}
\hline & Alcoi (1598) & Penàguila (1601-02) \\
\hline Trigo & 66,0 & 67,9 \\
\hline Cebada & 26,6 & 30,0 \\
\hline Avena & 6,3 & 1,0 \\
\hline Maíz & 2,1 & - \\
\hline Mixturas & - & 1,1 \\
\hline
\end{tabular}

Fuente: ARV-MR, 5.430: Terç delme d'Alcoi, 1598; i, 5.884: Terç delme de Penàguila, 1601-1602.

situación de paridad con respecto al trigo se mantendría, al menos, hasta la década de los treinta del siglo XVI en la villa de Alcoi $^{20}$.

En el umbral del siglo XVII, el retroceso del cultivo de la cebada ya se había consumado de forma definitiva. La información del Cuadro 2 es contundente al respecto $^{21}$. En Alcoi, dos tercios de la cantidad total de cereales producida correspondían al trigo, mientras la cebada se veía relegada a la cuarta parte. Destaca, asímismo, la presencia significativa de un cereal de primavera, la avena, destinada, exclusivamente, a piensos - de hecho no aparece nunca en los arrendamientos de

\footnotetext{
${ }^{20}$ Con todo, resulta probable también que el 50 por cien estricto marcado tradicionalmente en los arrendamientos en especie a lo largo del siglo XV-Arxiu del Regne de ValènciaSección Mestre Racional (desde ahora ARV-MR): Batllia d'Alcoi, 1444-1702; 1.115 a 1.296- se viese superado en la práctica, y que fuera precisamente esta razón la que forzara el cambio en la modalidad del arrendamiento a partir de 1536, introduciendo el pago en dinero.

${ }^{21}$ Para la metodología empleada en reconstruir los datos me remito a mi tesis doctoral: Torró Gil (2000, pp. 118-119).
} 
los molinos. En Penàguila, población situada en la zona oriental de la comarca, la situación es más acusada, ya que los cereales de primavera apenas tienen peso. El trigo supone más de dos tercios y la cebada ocupa un 30 por cien. Esta presencia significativa de la cebada se debe, con toda seguridad, a la composición de los cultivos de las alquerías moriscas comprendidas en su término.

Aunque el siglo XVI marcó un retroceso considerable de la cebada frente al trigo, éste no fue idéntico en todas partes. Los escasos indicios de los que dispongo indican que en las localidades de cristianos viejos el proceso fue mucho más rápido que en las de moriscos. Por ejemplo, las recaudaciones en especie de cereales del tercio diezmo de la baronía de Planes, situada como Penàguila en la zona oriental, a mediados de siglo reflejan claramente lo que estoy apuntando -v. Cuadro 3. Los cristianos viejos se habían inclinado ya claramente por el trigo, mientras que los moriscos mantenían una ligera preferencia por la cebada. De hecho, cabe matizar la igualdad que refleja el cuadro para las alquerías moriscas, ya que, en los años siguientes, la cebada supera claramente al trigo en las recaudaciones señoriales ${ }^{22}$. Asimismo, destaca la ligera proporción que representan las mixturas en el caso de Planes y su inexistencia en los lugares de moriscos. El resto de cereales tendría una escasa presencia.

\section{CUADRO 3}

RECAUDACIÓN DE CEREALES EN ESPECIE (PORCENTAJES). TERCIO DIEZMO DE PLANES Y SUS ALQUERÍAS, 1561

\begin{tabular}{|l|c|c|}
\hline & Planes & $\begin{array}{c}\text { Llombo, Margarida, Benicapcell, } \\
\text { Catamarruch, Benialfaquí } \\
\text { y Almudaina }\end{array}$ \\
\hline Trigo & 67,3 & 50,7 \\
\hline Cebada & 31,3 & 49,3 \\
\hline Mixturas & 1,4 & - \\
\hline
\end{tabular}

Fuente: ARV-MR; 10.168: Segrest de la Baronia de Planes, 1560-1563.

Por lo que parece, pues, el retroceso de la cebada frente al trigo no se ve correspondido con el ascenso de otro cereal durante el Quinientos. La información

${ }^{22}$ Este sesgo puede deberse a una tasación diferente -que desconozco- entre el tercio diezmo y las recaudaciones señoriales. La utilización en el cuadro de las cifras del tercio diezmo responde a un deseo de permitir la comparación, puesto que los contribuyentes de la villa de Planes estaban exentos de las particiones por su condición de cristianos viejos. En 1562 y 1563 las recaudaciones señoriales de trigo y cebada en las alquerías fueron respectivamente de 873,125 y 1.330,625 barchillas, y de 1.629,75 y 1878,75; es decir, en proporción de 40/60 y 46/54, en cada uno de los años. 
recogida de los tercios diezmos de Penàguila y Planes - con mayoría de población morisca- no apoya la hipótesis de Primitivo Pla (1996, pp. 208) sobre la pronta adopción del maíz entre los cristianos nuevos. Las inciertas noticias sobre la dieta de los moriscos ${ }^{23}$ y sus formas y tipos de cultivos no permiten afirmar nada con certeza. Es probable que Pla tenga razón, pero, de todos modos, parece que la adopción no sería un fenómeno tan generalizado como él sostiene. Por la información de la que dispongo, sí que parece, en cambio, que la cebada desempeñara un papel mucho más destacado en la agricultura y, por lo tanto, en la alimentación morisca que en la de los cristianos ${ }^{24}$. Además, el único lugar de la pequeña muestra que utilizo en el que se detecta una introducción temprana del maíz es la propia villa de Alcoi, donde, como hemos visto, en 1598 ya representaba un 2,1 por cien del total de los cereales ${ }^{25}$.

La evolución del siglo XVI, en el ámbito de los cereales, presenta, por lo tanto, una serie de rasgos destacables. En primer lugar, la progresiva reducción del peso de la cebada en el conjunto de la producción. En segundo lugar, que este fenómeno se reduce, sobre todo, a las localidades de cristianos viejos, mientras que en las moriscas el proceso no se daría con la misma intensidad o, a lo sumo, se verificaría en fechas más avanzadas. En última instancia, se trata de una sustitución de cebada por trigo, sin que intervenga ningún otro cereal. La introducción del

\footnotetext{
${ }^{23}$ Casey (1981, p. 71).

${ }^{24}$ En el caso de la Foia de Lombai estudiado por Ardit (2004, pp. 64-66) se aprecia también que, a lo largo del siglo XVI, los moriscos prefirieron cultivar cereales «menores» -en este caso mijo y sorgo- antes que el trigo, con los que mantenían una situación de paridad aunque sometida a fluctuaciones interanuales.

${ }^{25}$ No obstante, este dato ha de ser puesto en una cierta cuarentena. Como se ha indicado muchas veces, el principal problema a la hora de identificar el cereal americano es el terminológico. Por regla general, el maíz sustituyó a algún cereal que existía previamente y tomó el nombre de éste. Es el caso, p. e., de Galicia, donde suplantó al mijo, y de aquí su nombre gallego: milho. El caso valenciano es un poco más complejo, ya que se identifica con dos nombres diferentes, tomados, a su vez, de dos cereales que se cultivarían con anterioridad: el panís (mijo) y la dacsa (sorgo). En Alcoi, el nombre con el que se le conoce es el de panís. Hasta 1627 -y teniendo presente la limitación de la información- la documentación distingue entre panís gros y panís menut. En el tercio diezmo de 1598 la cifra comprende los dos cereales -51 barchillas y 3,25 almudes en total. En la información que le sigue -años 1603 a 1606- se dan las cifras por separado, representando el gros el 93,5 por cien. En 1611 y entre 1616 y 1627, la distinción se mantiene, aunque en el epígrafe de menut no se anota ninguna recaudación. Los cuadernos de administración del tercio diezmo siguientes -a partir de 1652- ya no hacen ninguna distinción, refiriéndose al cereal como panís, sin más. Creo que podemos suponer, sin demasiado riesgo a equivocarnos, que el panís gros es el maíz americano, y el menut, el cereal autóctono. La información que aporta Iborra (1981, pp. 98-102) sobre Sagunto lo corrobora. El baile de Morvedre escribía en el libro de administración del tercio diezmo de 1617 lo siguiente: «[...] entenent per dacsa la que dihuen dacsa grossa y per altre nom dacsa de les Índies, jatsià en Morvedre li dihuen panís, si bé lo que pròpiament se diu panís és un grà més menut y negre que no se'n cull may en Morvedre, y que si se ha cullit alguna dacsa de la blanca, se ha mesclat ab la grosa que és groga...» (p. 102). Si así fuese, la introducción del maíz se habría verificado en Alcoi a finales del s. XVI y, de forma definitiva, después de la expulsión de los moriscos.
} 
maíz se produciría, por consiguiente, de forma tardía y, probablemente, antes en las localidades de cristianos viejos que en las moriscas. De todos modos, en los inicios del siglo XVII este proceso sería todavía desdeñable en términos generales.

Esto es muy importante, porque supone que el progresivo abandono del cultivo de la cebada no se basa en cuestiones técnicas de alternancia en rotaciones en el regadío. Al contrario, desde el estricto punto de vista de la subsistencia, la cebada presenta muchas ventajas respecto al trigo ${ }^{26}$. Por un lado, es mucho menos exigente con los suelos: sin llegar a los extremos del centeno -cereal que prospera muy bien en terrenos pobres y secos-, las zonas de secano con arena arcillosa y/o terreno calcáreo son plenamente aptas para su cultivo. Además, sus rendimientos son superiores a igualdad de condiciones, tanto en términos de ratio grano sembrado/grano recogido como por hectárea, dado que se puede sembrar con un poco más de densidad ${ }^{27}$. La cebada requiere abonos con menor intensidad que el trigo. Por otra parte, la cebada es apta tanto para el consumo humano como para el ganado. Únicamente desde el punto de vista nutritivo se aprecia una clara superioridad del trigo, aunque la diferencia está muy lejos de la que indican los precios relativos $^{28}$. Por lo tanto, no hay nada «natural» que explique el arrinconamiento de la cebada a lo largo del período que estamos estudiando. Las razones han de buscarse, pues, en el ámbito técnico y social.

La preferencia generalizada por el trigo en lugar de la cebada tampoco parece rendir cuentas de la cuestión. Como demuestra Comet (1992, pp. 323-326), la idea de una pretendida bondad del pan de trigo sobre el resto de cereales panificables es muy antigua. Siguiendo este razonamiento, por lo tanto, el trigo debería haber sido siempre el cereal predominante. Lo que habría que explicar, pues, es el predominio de la cebada y no su sustitución por el trigo. Parece evidente que, dado que su diferencia en valor nutritivo no es suficiente como para ser el determinante de los precios, la única razón que puede explicar la diferencia entre el valor de cambio del trigo y la cebada es su coste de producción. Es decir, simplificando, el trigo sería un cereal mucho más caro, dados sus débiles rendimientos, su mayor dificultad de adaptación a suelos pobres y su mayor exigencia de abonos y agua ${ }^{29}$. Por esta

\footnotetext{
${ }^{26}$ Comet (1992, pp. 193-326).

${ }^{27}$ Además de la obra ya citada de Comet, se pueden encontrar ejemplos comparativos de rendimientos -siempre favorables a la cebada, y frecuentemente con amplitud- en García Sanz (1986, p. 158) -rendimientos por superficie, 1678 y 1810- y en Tello (1995, pp. 302, 305 y 326) -rendimientos por unidad de semilla sembrada, ejemplos del s. XVIII y principios del XIX.

${ }^{28}$ Según Comet (1992, p. 322), en términos nutritivos la proporción entre trigo y cebada sería de 10 a 8 -se trata de una medida llamada U.F. (unidad forrajera). En cambio, la diferencia de precios iría mucho más allá de esta ratio de 1,25, situándose en el período que nos ocupa -precios de Alcoi- entre un 2,8, alrededor de 1446, y 2, en 1806 (Torró Gil, 2000, p. 215).

${ }^{29}$ Cavanilles (1795-97, II, p. 156) señalaba, refiriéndose a algunas zonas de la Baronía de Planes, que «[...] como el suelo es pobre y carece de riego, solo prosperan las cebadas y muy poco los trigos [...]». De hecho, un poco antes ya había apuntado que uno de los principales problemas del término era la escasez de abonos; en estas condiciones, «[...] la cosecha de granos apénas basta para el sustento de los vecinos [...]» (p. 155).
} 
misma razón, y en el contexto de una progresiva concentración de la propiedad de la tierra, es normal que su mayor valor lo hiciera preferible, en principio, para las explotaciones orientadas al mercado. Por contra, la cebada sería el cereal de secano más propio de las explotaciones de autosubsistencia ${ }^{30}$. El ejemplo de las localidades moriscas, que tendrían como principal vínculo económico con el mundo cristiano la exigencia de renta de sus señores feudales, es bastante ilustrativo. La agricultura morisca mantuvo durante más tiempo la preferencia de la cebada, ya que garantizaría mejor las necesidades de subsistencia y reproducción de la comunidad ${ }^{31}$.

La evolución de los precios relativos indica, además, que a lo largo de los siglos XV y XVI podrían haberse introducido mejoras en el cultivo del trigo que aumentaron su rentabilidad con respecto a la de la cebada. Así, si en 144550 la relación entre el precio medio del cahíz de trigo y el de cebada era de 2,78, en 1523-32 era de 2,61 y en 1603-06, de 2,0932. Es evidente, por lo tanto, que el crecimiento del precio de la cebada fue mayor que el del trigo; paralelamente, en cambio, parece probable que la producción bruta de cebada creciese muy por debajo de la del conjunto de los cereales y de la agricultura en general, o, incluso, que localmente se estancara o aun disminuyera ligeramente. Asimismo, también es lógico suponer que, al compás de la extensión del trigo, la parte de cebada destinada a usos forrajeros aumentara. Por todo ello, podemos suponer que, por un lado, el trigo desplazó a la cebada de las mejores tierras campas del secano y, por otro, que el cultivo del trigo se extendió notablemente en el regadío. Es posible, también, que la cebada se mantuviese como el cereal preferido para valorizar las tierras de secano puestas en cultivo recientemente $^{33}$. Todo esto habría de contribuir a que los rendimientos medios de la cebada decrecieran más rápidamente que los del trigo y, con ello, también la productividad del trabajo invertido.

${ }^{30}$ Este extremo es fácilmente comprobable en el caso castellano estudiado por Yun. En la Tierra de Campos del siglo XVI, no sólo se aprecia que las explotaciones mayores dirigían una cantidad mucho mayor de cereal hacia el mercado, sino que el predominio del trigo en las ventas era absoluto (Yun, 1987, p. 145).

${ }^{31}$ Las enormes diferencias entre la agricultura morisca y la cristiana -en este caso entre antes y después de la expulsión- se pueden observar claramente en el caso de la Foia de Llombai (Ribera Alta) estudiado recientemente por Ardit (2004, pp. 64-71 y 103116).

32 Vid. nota 21.

33 Según Comet (1992, pp. 244-265), tanto el centeno como la cebada son cereales que, por sus escasas exigencias edáficas e hídricas, pueden prosperar perfectamente en tierras recientemente puestas en cultivo. Dada la práctica inexistencia del centeno durante el s. XVI, debemos suponer que era la cebada la que cumplía este papel. 


\section{ROTACIONES DE CULTIVOS Y DIVERSIFICACIÓN DE LA PRODUCCIÓN AGRARIA}

El valor más elevado del trigo habría facilitado, pues, su colonización de las zonas irrigadas. Hasta la introducción del maíz, cabe pensar que la forma predominante del cultivo cerealícola en el regadío fuese el régimen de cultura promiscua, básicamente con cultivos arbóreos ${ }^{34}$. Esta práctica sería frecuente incluso en tierras de secano, y el cultivo con el que se asociaría con más frecuencia sería el del olivo. De hecho, Cavanilles (1795-97, II, pp. 155) aún constata a finales del s. XVIII estas formas de conducción de la tierra en el secano de la baronía de Planes:

«Las inmediaciones de Planes presentan terrenos desiguales, pero de mucho fondo, y bien plantados de robustos olivos que rinden abundantes cosechas. No solamente se ven allí los árboles muy cargados de fruto, sino mieses preciosas hasta debaxo de la sombra que ellos hacen; lo que depende del método con que aquellos hombres cultivan sus campos. Por Octubre y Noviembre, tiempo de sembrarlos, ponen ordinariamente al pie de cada olivo dos ó tres cargas de estiercol, dando así nueva substancia al árbol, y enriqueciendo el suelo para que los trigos crezcan con lozanía.»

La asociación del olivo con otros cultivos se documenta también muy frecuentemente en los arrendamientos alcoyanos de los primeros años del siglo XVII; de la misma manera, la fuerte presencia de olivares en las partidas regadas del término de Alcoi apunta en el mismo sentido ${ }^{35}$.

El aceite era uno de los principales productos del campo valenciano a lo largo del s. XVI y, también, uno de los que eran objeto de un tráfico más intenso ${ }^{36}$. Como se puede apreciar en el Cuadro 4, el aceite era el tercer producto agrario por su valor en las alquerías moriscas de Planes a finales del segundo tercio del s. XVI, y, asimismo, en el término de Penàguila -alquerías incluidas- a principios del siglo XVII. El caso de Alcoi aún es más llamativo, ya que el aceite se sitúa en el segundo lugar por creación de valor, superando, incluso, a la misma cebada. Destaca también, en los tres casos, la escasa proporción que supone el capítulo de otros $^{37}$. También resulta

\footnotetext{
${ }^{34}$ En las llanuras aluviales valencianas era frecuente la asociación del cultivo de cereal -trigo, sobre todo, pero también arroz- con las moreras destinadas a la producción de seda: Véanse Ardit (1996, p. 69) y Peris (2003, p. 90). Este sistema era muy similar al utilizado en el valle del Po, la llamada piantata padana, según indica Ardit (1992, p. 56)

35 Torró Gil (1994, pp. 25-27).

${ }^{36}$ En algunas zonas constituía, en la práctica, el eje sobre el que descansaba la agricultura comercial, particularmente en Elx; v. Serrano (1993, pp. 63-67). Es llamativo el hecho de que en este caso, como en Elx, sean los moriscos sus principales productores.

${ }^{37}$ En este apartado he incluido lo que en Penàguila y Planes llamaban Sant Miquelada, y que en Alcoi se incluye bajo el epígrafe conjunto de paner $i$ vi.
} 
relevante el escaso peso que tenía la producción de vino en la zona a finales del siglo XVI. Y no sólo por la importante presencia de moriscos; tampoco en las localidades de cristianos viejos el cultivo de la viña había alcanzado aún unas dimensiones considerables.

\section{CUADRO 4}

APROXIMACIÓN A LA ESTRUCTURA DE LA PRODUCCIÓN AGRARIA (VALOR EN PORCENTAJES). ALCOI, PENÀGUILA Y ALQUERÍAS MORISCAS DE PLANES (CON ALCOLEJA), 1561-1606

\begin{tabular}{|l|c|c|c|}
\hline & $\begin{array}{c}\text { Alcoi Tercio diezmo } \\
\text { (1603- 1606) }\end{array}$ & $\begin{array}{c}\text { Llombo, Margarida, } \\
\text { Penàguila Tercio } \\
\text { diezmo (1602-1603) }\end{array}$ & $\begin{array}{c}\text { Benicapcell, Catamarruch, } \\
\text { Benialfaquí, Almudaina y } \\
\text { Alcoleja. Recaudaciones } \\
\text { señoriales (1561) }\end{array}$ \\
\hline Trigo & 65,2 & 74,4 & 51,0 \\
\hline Cebada & 11,7 & 13,9 & 24,1 \\
\hline Maíz & 4,1 & - & - \\
\hline Avena & 1,3 & $0,4-$ & - \\
\hline Mixturas & 0,6 & 0,6 & 21,4 \\
\hline Aceite & 13,4 & 8,1 & 3,6 \\
\hline Otros & 3,7 & 2,6 & \\
\hline
\end{tabular}

Fuente: ARV-MR, 10.168: Segrest de la Baronia de Planes, 1560-1563; ARV-MR, 5.884: Terç delme de Penàguila, 1602-1603; ARV-MR, 5.431 a 5.434: Terç delme d'Alcoi, 1603 a 1606.

La expulsión de los moriscos en 1609 contribuirá decisivamente a alterar este panorama. Por un lado, con la profundización de algunas de las tendencias que se habían ido apuntando, y, por otro, con la aparición de otras nuevas. La persistencia del retroceso del cultivo de la cebada se ha de enmarcar en el primer apartado, mientras que en el segundo tendremos, sobre todo, la extensión del cultivo de la viña y la producción de vino y derivados. A caballo entre los dos, y como la característica más importante, la colonización del regadío por una típica rotación de cultivos que acrecentaría de forma notable los rendimientos de estas tierras: la alternancia de trigo, maíz y leguminosas. Todo ello en el marco de una progresiva diversificación de cultivos que no resultó incompatible, a largo plazo, con una cierta especialización local. 


\section{CUADRO 5}

\section{APROXIMACIÓN A LA ESTRUCTURA DE LA PRODUCCIÓN AGRARIA} (VALOR EN PORCENTAJES). TERCIO DIEZMO DE ALCOI Y PENÀGUILA, 1616-1630

\begin{tabular}{|l|c|c|}
\hline & Alcoi (1616-1627) & Penàguila (1629-1630) \\
\hline Trigo & 66,7 & 79,0 \\
\hline Cebada & 10,4 & 8,8 \\
\hline Maíz & 2,5 & - \\
\hline Mixturas y centeno & 0,2 & 1,9 \\
\hline Avena & 1,8 & 0,3 \\
\hline Aceite & 10,5 & 4,9 \\
\hline Vino & 5,1 & - \\
\hline Anís & 1,1 & 1,9 \\
\hline Paner & 1,1 & - \\
\hline Otros & 0,6 & 3,2 \\
\hline
\end{tabular}

Fuente: ARV-MR, 5.435 a 5.446: Terç delme d'Alcoi, 1616 a 1627; ARV-MR, 5.900 a 5.901: Terç delme de Penàguila, 1629 i 1630.

Tanto en Alcoi como en Penàguila ${ }^{38}$-únicos lugares documentados- la situación ha empezado a cambiar en los años inmediatos a la expulsión, especialmente en el caso alcoyano. Como muestra el Cuadro 5, se aprecia una tendencia a la diversificación. Con todo, destaca, en primer lugar y en los dos casos, el peso creciente del trigo, así como el descenso de la cebada y el aceite ${ }^{39}$. Es destacable, asimismo, el descenso importante del maíz en Alcoi y el hecho de que su cultivo no se haya iniciado aún en Penàguila. Las notas más destacadas son el aumento del vino, especialmente en Alcoi ${ }^{40}$, y la aparición de un cultivo que adquirirá cierta relevancia a lo largo del siglo XVII y que, seguramente, se relaciona con el cre-

\footnotetext{
${ }^{38}$ Hay que tener en cuenta que la muestra es mucho menos representativa en el caso de Penàguila que en el de Alcoi, por contar únicamente con dos años. Esto supone que alguna producción se encuentre claramente infrarepresentada; es el caso, sobre todo, del aceite, ya que, al tratarse de una producción extremadamente irregular -v. Torró Gil (1994, pp. 90-91) -, el contar con años de mala cosecha -como parecen ser estos dos- puede distorsionar su representatividad. Por esta razón matizaré los datos de 1629-30 con los de 1643, el año más cercano para el que dispongo de información.

${ }^{39}$ Aunque en el caso de Penàguila, como he señalado en la nota precedente, quizá estas tendencias estén un poco magnificadas. De hecho, en 1643 el valor del aceite representaba un 9,68 por cien y el de la cebada un 13,96 por cien, muy cercanos a los de 1602-03.

${ }^{40}$ En Penàguila se encuentra dentro del capítulo de otros, por pagarse aún dentro de la Sant Miquelada. En 1643, en cambio, cuando ya aparece por separado representa un 1,77 por cien.
} 
cimiento de la producción de vino: el anís, mucho más importante en Penàguila que en Alcoi. Parece probable que su cultivo tuviese como finalidad última la aromatización del vino o, especialmente, del aguardiente. De hecho, es significativo que su cultivo progresara notablemente hacia finales de siglo en Penàguila, donde la producción de vino se mantuvo en auge, mientras que desaparece en Alcoi, donde la viña parece contraerse en la segunda mitad del s. XVII.

Aunque quizá esta diversificación se vea un tanto magnificada por las fuentes $^{41}$, parece incontestable el progreso de la producción de vino -y de anís-, así como de trigo, frente a la reducción del resto. Hacia finales del siglo-v. Cuadro 6-, en un contexto de crecimiento de la producción y de caída de los precios, algunos de estos rasgos se han consolidado plenamente. El retroceso de la cebada y el aceite continúa lenta pero implacablemente, por un lado. Por otro, el avance correlativo del maíz y los otros cereales: la avena y el centeno en el caso alcoyano, las mixturas en el de Penàguila. Del mismo modo, mientras que en Alcoi el peso del trigo se ha mantenido invariable en términos relativos, en Penàguila ha retrocedido de forma notable. Paralelamente, observamos un fenómeno que no se ha producido en Alcoi: el progreso de otras producciones. Así, mientras que el paner y otros -fundamentalmente legumbres y algunas hortalizas-producían el 1,8 por cien del valor agrario en el Alcoi posterior a la expulsión, en la época de la Segunda Germanía esta proporción se había reducido a un 0,7 por cien. En cambio, en Penàguila, donde el capítulo de legumbres, frutas y hortalizas aún representaba un 1 por cien en 1643, entre 1678 y 1682 había pasado a suponer un 1,4 por cien.

De todas las transformaciones de la agricultura de esta villa y su término, las más significativas son la introducción del maíz -tardíamente, después de 1643- y el progreso de la producción de vino y anís. No deja de sorprender la proporción que llega a representar este último cultivo en el conjunto del valor, un 7,1 por cien, lo que indica a las claras un cierto grado de especialización. Como en el caso alcoyano, por lo tanto, se observa, al mismo tiempo, una especialización y una diversificación. Las producciones se hacen más variadas a causa de la introducción de nuevas formas de conducir la tierra que implican el policultivo, pero esto no es contradictorio con la tendencia expansiva de algún producto específico que, por sus dimensiones, conlleva una orientación claramente comercial, con independencia de la distancia a la que se sitúen sus mercados de destino. De igual modo, si pudiésemos extender el campo de observación, seguramente apreciaríamos especializaciones paralelas en otros lugares de la comarca -o incluso más allá- que compensarían en parte las disminuciones relativas que se observan aquí.

${ }^{41}$ En un marco de contracción de la rentabilidad de las rentas diezmales, es muy probable que los recaudadores se esforzaran por obtener el máximo provecho de todas y cada una de las producciones y, por ello, intensificaran el control. Vid. Torró Gil (2000, pp. 187-188). Para el conjunto del país destacan los trabajos de Palop (1982) y de Ardit (1987). 


\section{CUADRO 6}

APROXIMACIÓN A LA ESTRUCTURA DE LA PRODUCCIÓN AGRARIA (VALOR EN PORCENTAJES). TERCIO DIEZMO DE ALCOI Y PENÀGUILA, 1678-1694

\begin{tabular}{|l|c|c|}
\hline & Alcoi (1691-1694) & Penàguila (1678-1682) \\
\hline Trigo & 66,6 & 67,0 \\
\hline Cebada & 6,8 & 7,3 \\
\hline Maíz & 7,6 & 1,2 \\
\hline Mixturas & - & 5,5 \\
\hline Centeno & 2,4 & - \\
\hline Avena & 4,9 & 0,4 \\
\hline Aceite & 7,6 & 6,9 \\
\hline Vino & 3,4 & 3,2 \\
\hline Anís & - & 7,1 \\
\hline Frutas & 0,3 & 0,4 \\
\hline Legumbres & - & 1,0 \\
\hline Otros & 0,4 & - \\
\hline
\end{tabular}

Fuente: ARV-MR, 5.452: Terç delme d'Alcoi, 1691 a 1694; ARV-MR, 5.921 a 5.925: Terç delme de Penàguila, 1678 i 1682.

En el caso alcoyano, la introducción del maíz debe relacionarse, sin lugar a dudas, con la nueva rotación de cultivos en el regadío. Este fenómeno se generalizaría puesto que, a finales del siglo XVIII, Cavanilles y otros observadores lo constatan en casi todos los lugares de la comarca. Un sistema de este tipo es descrito por el botánico en la huerta de Onil en la que se obtenían

«[...] siempre dos cosechas de este modo. Siémbrase el trigo en tiempo regular, y sigue sus épocas hasta llegar á la perfeccion: segado y levantadas las mieses, vienen otros trabajadores que aran el campo, y lo siembran de maiz. Quando este tiene aun el fruto verde entran otros de nuevo y en el mismo campo siembran habas, que se hallan muy crecidas al coger el maiz, y á continuacion se prepara el campo para sembrar el maiz, que madura ántes de cumplirse dos años desde que se sembró el trigo.» ${ }^{42}$

\footnotetext{
${ }^{42}$ Cavanilles (1795-97, II, pp. 176-177).
} 
Esta forma de conducción de la tierra es citada expresamente en L’Orxa, el Comtat en general, $\mathrm{Biar}^{43}$, Onil, Xixona ${ }^{44}$ y Alcoi. También resulta evidente, con todo, que una parte importante del trigo se cultivaba aún en el secano, así como que el maíz no siempre estaba integrado en rotaciones, como parece ser el caso de la misma Penàguila ${ }^{45}$.

Sin embargo, los elevados rendimientos que se obtenían provocarían que, en la época de Cavanilles, la mayor parte del trigo y del maíz proviniera de estas tierras. Según los cálculos de M. Ardit (1993, pp. 39), los rendimientos citados por Cavanilles en la huerta de Onil -«[...] de diez á catorce cahices de trigo, y otros tantos de maíz [...]», por jornal ${ }^{46}$ - equivaldrían a una cantidad situada entre $40 \mathrm{y}$ $56 \mathrm{hl} /$ ha. La detallada información que, por su parte, proporciona Carlos Beramendi (1994, pp. 178-180) sobre la huerta de Cocentaina ofrece rendimientos importantes, aunque no tan elevados. Este viajero, al referirse a la primera «fila» de agua de riego, nos describe las características y los rendimientos de la rotación en la huerta contestana en los siguientes términos:

«[...] se siembran tres almudes o celemines de trigo en cada fanega de tierra, y produce en un año bueno un caíz y medio, o dieciocho barchillas de a cuatro celemines cada una: en el mismo año, luego que se corta el trigo, se siembran tres medios celemines de panizo y medio de alubias, y se cogen de estas, dos, o tres, barchillas, y de panizo tanto como de trigo [...]» ${ }^{47}$

Traducido en rendimientos por superficie, implica 36 hl/ha de trigo y maíz, a lo que se añadiría entre 4 y $6 \mathrm{hl} / \mathrm{ha}$ de alubias, siendo las proporciones en términos cosecha/siembra, respectivamente, de 24:1, 48:1 y entre 16 y 24:1. Se trata de las mejores tierras; en las peores de la huerta no pasarían de $18 \mathrm{hl} / \mathrm{ha}$, es decir, 12:1 para el trigo y 24:1 para el maíz. Dado que Beramendi nos describe toda la huerta de

43 «[...] frutales y moreras en los inferiores de riego, dexando área para trigos y maices, que se suceden en el mismo año». Cavanilles (1795-97, II, pp. 169).

${ }^{44}$ «[...] allí $[\ldots]$ siembra trigos, maices y hortalizas que se suceden sin interrupcion [...]». Cavanilles (1795-97, II, pp. 187).

${ }^{45}$ Posiblemente sea ésta la razón por la que tardó tanto en introducirse en la zona. De todos modos, la producción de maíz en Penàguila y sus alquerías no era irrelevante a finales del s. XVIII. Fundamentalmente se daba en tierras altas y sin riego, de rendimientos muy elevados, pero con una baja productividad del trabajo. Según Cavanilles, en las faldas de la sierra Aitana, sobre la propia Penàguila «[...] admiraban las producciones que en tal altura, privada enteramente de riego, cubrian el suelo; excelentes trigos, cebadas, mucho maiz, y mayor cantidad de garbanzos, con tanta lozanía como en los campos mas fértiles y privilegiados. Cáusalo lo fresco de las noches y las freqüentes nieblas que humedecen el suelo hasta que el sol adquiere bastante fuerza para disiparlas [...]; [en estos campos] no pueden subir caballerías, y por eso se hacen á brazo todas las labores.» Cavanilles (1795-97, II, pp. 199-200).

${ }^{46}$ Cavanilles (1795-97, II, pp. 173).

${ }^{47}$ Beramendi (1994, p.178). 
Cocentaina, podemos calcular los rendimientos medios ponderados que se obtenían en sus 389 jornales -unas 194 ha-, en unos 24hl/ha de trigo. Según estos datos, en un año bueno la huerta de la villa condal podía producir alrededor de 2.300 cahíces de trigo y otros tantos de maíz; si tenemos en cuenta que Cavanilles, en unas fechas muy cercanas, cifra estas producciones en 1.600 y 1.300 cahíces, podemos suponer que la práctica totalidad del trigo y todo el maíz se producían en el regadío ${ }^{48}$.

Con todo, a la postre las limitaciones físicas tenían que imponer, al compás de la extensión del mercado, una cierta especialización. Ésta vendría a ser más acusada cuanto mayor fuera el grado de acumulación de riqueza en las diferentes localidades. Ya hemos tenido ocasión de comprobar las diferencias entre la agricultura cristiana y la morisca en la baronía de Planes en el s. XVI. Aunque, si tenemos en cuenta la descripción de Cavanilles de finales del XVIII, en este diferente comportamiento representarían algún papel las características de la superficie cultivable, también es cierto, no obstante, que el arrinconamiento de los moriscos en las peores tierras no es un proceso «natural» ${ }^{49}$. Esto es claramente comprobable en el caso de Alcoleja, localidad que en el s. XVI producía mucha más cebada que trigo ${ }^{50}$, y donde, en cambio, a finales del siglo XVIII, el 76,5 por cien del cereal que se recogía era trigo ${ }^{51}$.

${ }^{48}$ El secano daría, pues, otras cosechas, como el vino -36.000 cántaros-, o el aceite -4.500 arrobas. Aunque las cifras puedan parecer contradictorias, en realidad no lo son. Hay que tener presente que Beramendi se refiere a la huerta de Cocentaina como si únicamente se cultivaran en ella trigo, maíz y alubias. En realidad, según Cavanilles, las producciones de este espacio irrigado serían más abundantes y variadas: «En estos campos, como en el resto de la huerta, se hacen al año dos cosechas principales, que son trigo y maiz, sin contar lo que rinden las moreras y frutales. Hay muy cerca de 600 hanegadas de alfalfa, que producen al año 30.000 pesos y otras donde se varían las producciones, como judias, melones y hortalizas»; sólo entre frutas y hortalizas, Cavanilles (1796-97, II, p. 160) habla de una producción de unas 200.000 arrobas. De hecho, refiriéndose al Condado de Cocentaina en general, lo describe en los siguientes términos: «[...] las viñas, los olivos, las higueras, y tal qual almendro, como también dilatados sembrados ocupan el terreno que el riego no puede fecundar: las moreras, los frutales, los maices, alfalfas, trigos y hortalizas adornan las huertas». Cavanilles (1796-97, II, p. 158). Es evidente, por lo tanto, que lo que hace Beramendi es ofrecer los rendimientos de la cosecha más importante de la huerta como medida de su valor.

${ }^{49}$ En el caso de Planes es muy evidente que los cristianos disponían de las mejores tierras. Los campos más altos de la Baronía, donde, según Cavanilles (1796-97, II, p. 156), «[...] el suelo es pobre y carece de riego [...]», serían mayoritariamente los cultivados desde las alquerías del término. Sobre la distribución forzada del poblamiento mudéjar y cristiano en la zona a raíz de la conquista medieval catalana, v. Torró Abad (1989).

${ }^{50}$ En 1561, el 58,56 por cien de la recaudación en especie de cereales fue de cebada, frente a un 41,44 por cien de trigo. En 1562 las proporciones fueron de 54,19 por cien de cebada, 44,63 por cien de trigo, 0,87 por cien de espelta y 0,31 por cien de centeno; ARV-MR, 10.168: Segrest de la Baronia de Planes, 1560-1563.

${ }^{51}$ En este caso, además, a pesar de tener una huerta importante de 70 jornales de extensión -2,46 hanegadas por vecino, frente a las 1,945 de Cocentaina, por ejemplo, o las 1,71 de la vecina Benilloba- el maíz no se encontraría integrado en rotación con el trigo sino de forma marginal, ya que la producción de cereales que cita Cavanilles (1795-97, II, p. 203) es de 700 cahíces de trigo, 200 de mixturas y solamente 15 de maíz. 
En el proceso de especialización, pues, intervienen tanto las características de suelo y clima como el grado de concentración de la propiedad de la tierra y las relaciones de producción que se imponen. No hay que olvidar que la mayor o menor dedicación a este o aquel cultivo es un hecho que se verifica a escala individual, es decir, en el seno de la explotación agraria y que, por lo tanto, no depende exclusivamente de las condiciones «externas» de la renta y el mercado sino, en primera instancia, de la lógica de la reproducción familiar. Una vez satisfechas las exigencias fiscales de los diferentes poderes feudales y -en su caso- las de los propietarios de la tierra, la explotación campesina cumplirá con las propias de la subsistencia. La mayor o menor integración en el mercado -y las condiciones en que ésta se realiza- dependerá de la disponibilidad de tierras -en extensión y calidad- y de fuerza de trabajo, así como del grado de control sobre la propia explotación impuesto por las relaciones de producción dominantes ${ }^{52}$.

Valga como ejemplo la observación de los cultivos de Penàguila y sus antiguas alquerías a finales del s. XVII -v. Cuadro 7. La característica más destacable es la uniformidad que se observa en la tipología de los cultivos practicados, lo cual demuestra que nos encontramos frente al mismo tipo de agricultura, característica de un medio físico bastante uniforme. Sin embargo, las diferentes proporciones que representan en cuanto al valor demuestran tendencias dispares en lo que atañe a la orientación comercial de la producción ${ }^{53}$. Para empezar, aunque los cereales representan en conjunto una proporción semejante -76,4 por cien en Penàguila, 77,2 por cien en las alquerías-, su distribución interna es muy distinta. El peso del trigo es considerablemente menor en el segundo caso, y esta diferencia se magnifica en términos de producto físico: el trigo representaba en Penàguila el 71,66 por cien del volumen total de los cereales, mientras que en las alquerías esta proporción era del 59,76 por cien. Por contra, la cebada y las mixturas, que, conjuntamente, en Penàguila apenas suponían una quinta parte, en las alquerías suponían un tercio ${ }^{54}$. Lo mismo es aplicable al resto de producciones, dada la

${ }^{52}$ Para estas cuestiones resultan imprescindibles las aportaciones de Amit Bhaduri, como, por ejemplo, Bhaduri (1998).

${ }^{53}$ Debemos tener presente que el valor medio anual del diezmo del periodo considerado ascendía a 118.239 sueldos en Penàguila -69,68 por cien- y a 51.445 sueldos y 11 dineros en las alquerías -30,32 por cien. En términos de cociente valor del diezmo/vecino, con las cifras del morabatí de 1674 -ARV-MR, 10.907-, y estimando la población de Ares y Benasau desagregada de la de Penàguila a partir de los datos de la pragmática de 1692 -según Badenes y Bernat (1994, pp.193-194)-, los resultados son de 679,53 sueldos por vecino en Penàguila y de 605,25 sueldos por vecino en las alquerías.

${ }^{54}$ Las proporciones de cebada y mixturas suponían, respectivamente, en Penàguila un 13,93 por cien y un 9,72 por cien, y en las alquerías un 21,25 por cien y un 13,65 por cien. El centeno no se cultivaba en las alquerías y sólo aparece en Penàguila en una proporción muy reducida $-0,07$ por cien. El maíz pesa más en las alquerías -3,84 por cien- que en Penàguila -2,47 por cien-, al contrario de lo que pasa con la avena $-2,15$ por cien y 1,5 por cien, respectivamente. 
producción relativamente superior de vino, aceite, fruta y lana en Penàguila, y de legumbres y carne en las alquerías. La única excepción la constituye el anís que, con todo, era producido en mayor cantidad en Penáguila.

\section{CUADRO 7}

\section{APROXIMACIÓN A LA ESTRUCTURA DE LA PRODUCCIÓN AGRARIA \\ (VALOR EN PORCENTAJES). TERCIO DIEZMO DE PENÀGUILA Y LAS ANTIGUAS ALQUERÍAS DE SU TÉRMINO, 1678-1682}

\begin{tabular}{|l|c|c|}
\hline & Penàguila & Alcoleja, Ares, Benasau y Beniafé \\
\hline Trigo & 65,36 & 58,90 \\
\hline Cebada & 5,80 & 9,40 \\
\hline Maíz & 0,70 & 2,20 \\
\hline Mixturas & 4,50 & 6,70 \\
\hline Centeno & 0,04 & 0,10 \\
\hline Avena & 0,40 & 0,30 \\
\hline Aceite & 6,90 & 5,70 \\
\hline Vino & 3,60 & 1,80 \\
\hline Anís & 6,60 & 7,00 \\
\hline Frutas & 0,50 & 0,10 \\
\hline Legumbres & 0,70 & 1,60 \\
\hline Lana & 2,90 & 2,60 \\
\hline Carne & 2,00 & 3,60 \\
\hline
\end{tabular}

Fuente: ARV-MR, 5.921 a 5.925: Terç delme de Penàguila, 1678 i 1682.

La obra de Cavanilles nos proporciona un punto de referencia magnífico para apreciar el estado del proceso que he estado dibujando a finales del s. XVIII. De sus descripciones se desprende con claridad que la diversificación que se había verificado en las producciones agrarias de la comarca desde la expulsión de los moriscos se complementaba con una clara tendencia a la especialización, lo cual supone, por encima de todo, la existencia de un mercado de bienes agrarios bastante integrado aunque, de momento, de dimensiones modestas. Y, lo que resulta más significativo, que este mercado no se limitaba a los bienes comerciales «tradicionales» -cereales, vino y aceite-, sino que abarcaba una extensa gama de productos entre los que no ocupaban un lugar secundario los bienes perecederos. La clave la hemos de buscar en la profundización de la división del trabajo y, como principal efecto de la misma, en la aparición de una serie de núcleos urbanos y semiurbanos en los que la ocupación agraria tiende a desplazarse en favor de otras, y muy particularmente de la manufactura. Entre estos núcleos destaca, lógicamente, la villa de Alcoi, una verda- 
dera ciudad en la que se concentraba en 1787, con sus 11.434 habitantes, el 22,87 por cien de la población de la comarca, siendo ya en aquellos momentos la séptima aglomeración urbana del País Valenciano, por detrás de -en este orden-Valencia, Alacant, Elx, Oriola, Xàtiva y Castelló de la Plana ${ }^{55}$.

Entre fruta y hortalizas, Cavanilles cita más de 500.000 arrobas producidas, mientras que, por establecer un punto de comparación, la producción de aceite apenas superaba las 80.000 arrobas. Aunque los precios medios podían tener una relación de 5:1 en favor del aceite, según se desprende del informe del ilustrado alcoyano Francesc Pérez Planelles (1807, pp. 26 y 28) -v. Apéndice-, las frutas y hortalizas aún superarían al aceite en casi un tercio de su valor. Es remarcable, no obstante, la obstinación de los historiadores en despreciar los flujos comerciales de este tipo de bienes agrarios. Y ello en contra de los testimonios de los contemporáneos que, como el mismo Cavanilles, no dejan de aportar indicios -cuantitativos y cualitativos- de su existencia. Como apunta, por ejemplo, él mismo para la villa de Xixona -a medio camino entre Alacant y Alcoi-,

«Allí crecen amistosamente el almendro y la morera, el naranjo y el olivo, el algarrobo, la palma y todo género de frutales, siendo tan grande la cantidad de frutas, que se regulan en 100 cargas de á ocho arrobas las que de allí salen cada noche para los pueblos de la comarca.» ${ }^{56}$

Me parece que esto deriva de un prejuicio contra los mercados de corto alcance, como si los únicos mercados importantes fueran los de los de larga distancia. No obstante, si se adopta el punto de vista del análisis de la «construcción» del mercado, estos espacios de intercambio comarcales adquieren una dimensión mucho más importante para bienes como los agrarios u otros -materiales de construcción, p.e. -, y para factores como la tierra y, particularmente, la fuerza de trabajo $^{57}$. El informe del ilustrado alcoyano Pérez Planelles demuestra fehacientemente este extremo. Por un lado, pone en evidencia la especialización agraria alcoyana. $\mathrm{Y}$, por otro, nos indica hasta qué punto estaba integrado el mercado comarcal de bienes agrarios. En el Apéndice figura la producción alcoyana y si los déficits se cubrían por la oferta comarcal.

La información sobre la producción y su valor se resume en el Cuadro 8. Los tres principales productos del campo alcoyano -trigo, maíz y vino- suponen el 92

${ }^{55}$ Hay que tener presente, además, su acelerado ritmo de crecimiento. En 1842 su población -25.315 habitantes, más del doble que 55 años atrás- ya era un tercio del total comarcal -33,82 por cien-, siendo en aquel momento la segunda ciudad del país y con 5.000 habitantes más que su inmediata seguidora, Alacant. Vid. al respecto Badenes y Bernat (1994).

${ }^{56}$ Cavanilles (1796-97, II, pp. 187-88). El subrayado es mío.

57 Sobre el concepto de «construcción» del mercado, aunque planteado para otro marco de análisis, el de las redes comerciales a larga distancia, resultan especialmente incisivas las reflexiones de Torras (1993). 
por cien del total de valor. Si lo comparamos con el Cuadro 6, nos daremos cuenta de cómo se ha producido un importante descenso relativo del peso del trigo, que sigue siendo, con todo, la principal producción, y de otros cereales como la avena, el centeno y la cebada. Si el primero pasa de representar un 66 por cien a tan sólo un 52 por cien del valor total, los otros tres juntos, que aún suponían un 14 por cien a fines del XVII, apenas alcanzan el 2 por cien. En volumen, no obstante, dentro del conjunto de cereales, el trigo apenas pierde peso -de un 63,1 por cien en $1691-94$ pasa a un 60,4 por cien-, mientras que la cebada se ha reducido a menos de la mitad -de un 11,9 por cien a un 4,2 por cien-, y los otros cereales que llegaron a representar un porcentaje significativo a finales del XVII -un 9,46 por cien la avena y un 2,94 por cien el centeno-, pasan a un irrelevante 0,7 por cien en conjunto, suponiendo la de la avena una reducción muy considerable ${ }^{58}$. El ganador sin paliativos es el maíz, que casi triplica su participación, tanto en el volumen de cereales producidos -de un 12,6 por cien a un 34,7 por cien-, como en el valor agrario total -de un 7,6 por cien a un 20 por cien. El otro cultivo que se impone con claridad es la viña, que ve multiplicada casi por seis su participación a lo largo del s. XVIII -del 3,4 por cien al 19,7 por cien ${ }^{59}$. Por lo que atañe al resto, destaca el crecimiento importante, dentro de su modesta contribución, del forraje, fruta, hortalizas y legumbres. En última instancia, se hace necesario destacar el retroceso continuo de la participación de la producción de aceite en el valor de la agricultura alcoyana, al pasar de un respetable 7,6 por cien en 1691-94 a un modestísimo 2,1 por cien en 1807.

\section{3. ¿UN CRECIMIENTO EXTENSIVO? ÁREA CULTIVADA, GANADERÍA Y PRO- DUCCIÓN DE ABONOS}

Resulta muy difícil delimitar hasta qué punto se extendió -o se contrajo- la superficie cultivada antes de mediados del s. XVIII, e imposible, por el momento, realizar cualquier estimación fuera del municipio de Alcoi. De la información que se desprende de las compraventas de tierras contenidas en los protocolos notariales, podemos suponer que, a principios del s. XVII, la mayor parte del valor agrario se producía en las tierras de secano, seguidas a mucha distancia, y en este orden, por la huerta, el olivar y, en última instancia, la viña ${ }^{60}$. En cambio, hacia

\footnotetext{
${ }^{58}$ Aunque utilizar cifras de un solo año siempre resulta peligroso, el ínfimo porcentaje que suponen es muy significativo. En el caso de la avena, aquél debe de relacionarse con una sustitución del forraje para la ganadería, especialmente la equina.

${ }^{59}$ Piqueras (1981, p. 54) atribuye este incremento y el del conjunto de la comarca, que se convirtió a lo largo del s. XIX en una de las principales zonas productoras de vino, al crecimiento demográfico alcoyano.

${ }^{60}$ Torró Gil (1994, p. 119).
} 


\section{CUADRO 8}

APROXIMACIÓN A LA ESTRUCTURA DE LA PRODUCCIÓN AGRARIA ( PORCENTAJES). ALCOI, 1807

\begin{tabular}{|l|c|c|}
\hline & Valor de la producción & Producción de cereales en especie \\
\hline Trigo & 52,26 & 60,40 \\
\hline Cebada & 1,80 & 4,20 \\
\hline Maíz & 20,00 & 34,70 \\
\hline Centeno & 0,30 & 0,60 \\
\hline Avena & 0,04 & 0,10 \\
\hline Aceite & 2,10 & - \\
\hline Vino & 19,66 & - \\
\hline Frutas & 1,50 & - \\
\hline Legumbres & 0,50 & - \\
\hline Forraje & 1,80 & - \\
\hline Hortalizas & 0,04 & - \\
\hline
\end{tabular}

Fuente: Pérez Planelles (1807, pp. 25-27).

1764 la situación es muy distinta -v. Cuadro $9^{61}$-, ya que en aquel momento el valor de la huerta ha crecido hasta igualar en la práctica el de los secanos productores de cereales, mientras que el olivar ha reducido su peso hasta situarse en el último lugar. Se puede comprobar cómo existe una notable diferencia entre la extensión que ocupa la huerta -un corto 6 por cien- y la renta que genera; según Pérez Planelles (1807, pp. 30) ello se debe a que «[...] no se conoce pueblo alguno de los de la Provincia cuyas tierras huertas, en igual cabida, produzcan tanto trigo, mahiz y avichuelas constantemente todos los años [...]». Las alteraciones que

${ }^{61}$ La información de 1764 proviene de un documento custodiado en el Archivo Municipal de Alcoi llamado Resumen general que contiene las utilidades de los vezinos de la villa de Alcoi, ganancias de sus tratos y averíos, y rentas de sus casas, artefactos, tierras y demás fincas -reproducción facsímil en Eines, $n^{\circ}$ 9-10, Alcoi, 1990, pp. 7-24. Las calidades se agrupan en «[...] suertes, espezies y calidades reguladas por jornales de seis mil trescientas varas valencianas quadradas superficiales cada uno [...]», del siguiente modo: dos suertes -las de mayor calidad, ambas de huerta- y nueve especies. De éstas, las cinco primeras -subdivididas en tres calidades cada una- son huertas, y las dos siguientes -también con tres calidades- son olivares. Las dos últimas -con tres y cuatro calidades, respectivamente- son las más complicadas de calificar, puesto que la octava no especifica nada y la novena sólo indica «secanos». He supuesto que la octava especie se refería a las viñas y la novena a las dedicadas a cereal. De hecho, la clasificación siguiente -la de 1807, referida en Pérez Planelles (1807, p. 30) - tan sólo se refiere a «huertas», «olivar», «viña» y «tierra secana de sembradura», aparte de la zona no cultivada. 
se advierten en 1807 no derivan exclusivamente de la sustitución de cultivos, sino que son fruto, también, de un notable crecimiento de la superficie cultivada. En efecto, como se puede observar en Cuadro 9, el área de cultivo aumentó en casi dos tercios, pasando de representar un 42,67 por cien del territorio local a un 70,57 por cien. El cultivo que más se expandió fue el de la viña, llegando a suponer una quinta parte de las tierras de labor. Del mismo modo, el regadío casi se duplicó, incrementando también su participación. En cambio, el crecimiento de la tierra campa se quedó por debajo de la media y el olivar se contrajo de forma muy notable.

\section{CUADRO 9}

SUPERFICIE CULTIVADA EN ALCOI, 1764 Y 1807

\begin{tabular}{|c|c|c|c|c|c|c|c|}
\hline \multirow[b]{2}{*}{ Calidad } & \multicolumn{4}{|c|}{1764} & \multicolumn{3}{|c|}{1807} \\
\hline & Hectáreas & $\%^{1}$ & $\begin{array}{c}\text { Renta } \\
\text { (en libras) }\end{array}$ & $\%^{1}$ & Hectáreas & $\%$ & $\begin{array}{l}\text { Incremento } \\
(1764-1807)\end{array}$ \\
\hline Cereal & $2.553,700$ & 70,90 & $12.784,530$ & 44,5 & $4.128,214$ & 69,30 & $\begin{array}{c}1.574,51 \\
(+61,65 \%)\end{array}$ \\
\hline Huerta & 216,687 & 6,00 & $11.931,520$ & 41,6 & 430,920 & 7,20 & $\begin{array}{c}214,033 \\
(+98,77 \%)\end{array}$ \\
\hline Viña & 528,222 & 14,70 & $2.447,450$ & 8,5 & $1.242,773$ & 20,90 & $\begin{array}{c}714,551 \\
(+135,27 \%) \\
\end{array}$ \\
\hline Olivar & 304,038 & 8,40 & $1.541,417$ & 5,4 & 156,280 & 2,60 & $\begin{array}{c}-147,758 \\
(-48,59 \%)\end{array}$ \\
\hline $\begin{array}{l}\text { Total } \\
\text { Cultivada }\end{array}$ & $3.602,647$ & 42,67 & $28.704,917$ & & $5.958,187$ & 70,57 & $\begin{array}{c}2.355,540 \\
(+65,38 \%)\end{array}$ \\
\hline Inculta & $4.840,512$ & 57,33 & & & $2.484,972$ & 29,43 & $\begin{array}{l}-2.355,540 \\
(-48,66 \%)\end{array}$ \\
\hline
\end{tabular}

Fuentes: 1764: Resumen general..., pp. 21-23. 1807 (Pérez Planelles, 1807, pp. 2930).

Notas:

${ }^{1}$ Los porcentajes de hectáreas y renta lo son sobre el total de superficie cultivada. Los porcentajes del «total cultivada» y «inculta» lo son sobre el total del municipio.

${ }^{2}$ El documento de 1764 no especifica el total de la superficie del territorio municipal. La cifra proviene, por lo tanto, en ambos casos, del informe de 1807. En cambio, este informe no indica el valor de la tierra.

Como no podía ser de otro modo, este aumento de la superficie cultivada tuvo su correlato en la disminución del número de cabezas de ganado. La comarca siempre había sido una zona bien dotada para la práctica de la ganadería lanar y cabría. Según los datos del censo de 1510 en la zona -incluyendo a la cercana Ontinyent-, había 111.132 cabezas, la mayor parte de los cuales serían, con toda seguridad, de 
estos tipos $^{62}$. En términos relativos, esto suponía un 11,34 por cien del total del país, con una media de cabezas por vecino de 36 , frente a unas 20 para el conjunto ${ }^{63}$. De hecho, un siglo más tarde, a pesar del crecimiento agrario que, con toda seguridad, supuso un fuerte empuje roturador, la zona seguía siendo una de las principales productoras valencianas de lana ${ }^{64}$. Con todo, los escasos datos de los que disponemos apuntan a que las dificultades del s. XVII no ayudaron en gran medida a la expansión de la ganadería, como hubiese cabido esperar de una coyuntura -al menos durante la primera mitad del siglo- en la que, probablemente, se contrajo la superficie cultivada. Si, en el caso de Alcoi, la ganadería representaba en el primer cuarto del s. XVI un 17 por cien del valor agrario, esta cifra se había reducido a un 8 por cien en los momentos posteriores a la expulsión y, tras una ligera recuperación, sólo representaba un 10 por cien en el tercer cuarto del s. XVII ${ }^{65}$. Esta evolución concuerda perfectamente con la del conjunto de la comarca ${ }^{66}$. Mientras que a inicios del s. XVI la ganadería producía la cuarta parte del valor agrario, en el último cuarto de dicho siglo y durante toda la centuria siguiente esta proporción se redujo a una décima parte. La ligera recuperación de la primera mitad del XVIII -relacionada, sin duda, con el auge pañero- se truncó rápidamente y, en su segunda mitad, la proporción se redujo a un 7,5 por cien.

Aunque resulta difícil generalizar por la falta de información, a la luz del caso alcoyano podemos suponer que la contracción de la ganadería vendría acompañada de un cambio importante en su orientación y en el tipo de animales que se criaban, así como por una tendencia a la especialización. En primer lugar, en lo que respecta a ovejas y cabras, los indicios apuntan a una disminución sensible de éstas a costa de aquéllas. En 1601, de los tres bovalars que tenía la villa de Alcoi, sólo se consentía el pasto sin restricciones en el Bovalar de Polop, el más alejado del recinto urbano, otro había desaparecido, el más próximo a la villa, el Bovalar de la Vall, y en el tercero, llamado Rebusca del Carrascar, el ganado cabrío tenía prohibido el acceso ${ }^{67}$. De hecho, en 1807 tan sólo pacían en el término 450 cabras, frente a unas 2.000 ovejas, y esta situación debía ser la predominante en la comarca, ya que el consumo de carne de cabra en la localidad ascendía a 4.000 cabezas, provenientes de Castilla ${ }^{68}$.

\footnotetext{
${ }^{62}$ No dispongo de ninguna referencia directa para afirmarlo; ahora bien, en los lugares en los que se conservan los cuadernos originales locales, así parecen indicarlo. Es el caso, p.e., de Sueca -localidad peor dotada físicamente para la práctica de este tipo de ganadería-, donde el 88,58 por cien del ganado citado en el censo era ovino o cabrío. Furió (1982, pp. 85-86).

63 García Cárcel (1976).

${ }^{64}$ Casey (1981, p. 87).

65 Torró Gil (1994, pp. 107-108).

66 Torró Gil (2000, pp. 147-148).

${ }^{67}$ Torró Gil (1994, pp. 31-32).

${ }^{68}$ Pérez Planelles (1807, pp. 24-25).
} 
Por otro lado, es muy probable que se extendiese de forma notable el ganado de corral y su comercio. Aparte de las aves, parece que la cría de cerdos representaría un papel de primer orden, tanto desde el punto de vista del autoconsumo campesino como en su orientación hacia el mercado. La presencia en las casas de los labradores alcoyanos de cerdos y otros animales de corral está bien documentada para los inicios del s. XVII, especialmente por la relativa abundancia de referencias que se registran en las actas notariales de pagos de dotes y creces en «cochinos» y «cochinas» ${ }^{69}$. A pesar de ello, el desarrollo urbano de Alcoi y su especialización haría desaparecer la cría de cerdos ya que, en 1807, Pérez Planelles (1807, pp. 24) estima la población de gallinas y palomos en 2.000 y 2.500, respectivamente, pero señala taxativamente que «[...] no hay ganado de cerda». En cambio, también señala más adelante que «[...] se matan al año 3.000 reses de ganado de cerda $[. ..] »^{70}$, lo cual implica un activo comercio de estos animales que, por sus características, debía desarrollarse en el ámbito comarcal.

El resto del ganado era fundamentalmente de tiro. Cabe destacar la progresiva desaparición de la ganadería vacuna: en 1807, al menos en Alcoi, Pérez Planelles (1807, pp. 24) indica que «[...] no hay bueyes, vacas, toros ni becerros [...]», y esta situación no era nueva, puesto que 40 años antes -en 1764- tampoco se hallan en el término ${ }^{71}$. Así pues, los bueyes de labranza, la presencia de los cuales aún tenía cierta relevancia a inicios del s. XVII ${ }^{72}$, fueron sustituidos completamente por mulos y asnos, que cubrían también las funciones de arriería ${ }^{73}$ : en 1807 su número ascendía en Alcoi, respectivamente, a 314 y $1.500^{74}$. Todos estos cambios no pueden desligarse de los cambios en los cultivos, puesto que la expansión del maíz facilitaría la alimentación de los animales de corral, mientras que la reducción de la cebada al papel de pienso podría haber constituido un punto de apoyo fundamental -junto al comercio de algarrobas (v. Apéndice)- para el avance de asnos y mulas.

Es evidente, por lo tanto, que la reducción constante de la cabaña ganadera tendría alguna repercusión sobre la producción de abonos. Entre 1510 y 1807 -únicos puntos posibles de comparación- la cantidad de animales en Alcoi pasó -excluyendo las aves de corral, que parecen no haberse tenido en cuenta en el censo de 1510- de 11.840 cabezas a 4.255, es decir, una reducción de un 63,97 por cien. Este descenso, no obstante, iba a ser compensado con creces por el crecimiento demográfico de la villa, que habría pasado de una población de unos 2.000

${ }^{69}$ Torró Gil (2000, p. 149).

${ }^{70}$ Pérez Planelles (1807, p. 25).

${ }^{71}$ Resumen general ... , p. 19.

72 Torró Gil (1994, pp. 30-31).

73 Éste es el único cambio técnico de consideración que Marcos (2000, pp. 72-75) admite para la agricultura española durante la Edad Moderna.

${ }^{74}$ Pérez Planelles (1807, p. 24). 
habitantes -440 vecinos- a una superior a los 13.000 en el mismo período. Esta era, según los observadores, una de las claves de los elevados rendimientos de la huerta alcoyana; Cavanilles insiste en ello ${ }^{75}$, pero el mejor testimonio, sin duda, lo aporta Pérez Planelles (1807, pp. 30), para quien los elevados rendimientos se debían al

«[...] mucho y excelente estiércol con que la abonan, y lo facilita la multitud de habitantes que tiene el pueblo, con particularidad los lugares comunes que tienen en sus casas; cuyo estiércol, mezclan con otros que todavía no han fermentado, y con paja de los corrales o destinada a arrojar a ellos, cuidando mucho de no desperdiciar cosa alguna, pues este abono es sin duda el mejor de los que deben usarse, porque aunque algunos dan la preferencia al de los palomares y gallineros, es insuficiente por su escasez para el abono de tantas tierras destinadas al cultivo.» ${ }^{76}$

Aunque con algunas particularides locales ${ }^{77}$, la situación puede hacerse extensiva al conjunto de la comarca ${ }^{78}$. De este modo, y particularmente en la segunda mitad del siglo XVIII, la superficie cultivada y, dentro de ella, el regadío, se habría extendido hasta el punto que hemos tenido ocasión de comprobar. Ahora bien, también resulta evidente que este tipo de agricultura tenía unos límites que no podían ser traspasados. A pesar de la intensidad del abono, ni siquiera en la villa de Alcoi podía superarse el barbecho fuera del regadío ${ }^{79}$, y aun en éste eran necesarias costosas prácticas de regeneración del suelo que Cavanilles observa en lugares como Cocentaina, Bocairent ${ }^{80}$ y Onil, o, como indica Beramendi (1994, pp. 164), en los campos alcoyanos, en los que «[...] sacan la tierra que está a media vara, o tres palmos de la superficie, para ponerla encima cuando se desustancia la que había $[\ldots] »$.

\footnotetext{
${ }^{75}$ Según él, «[...] por fortuna las fábricas y el gran número de vivientes de Alcoy suministran copia de estiercol». Cavanilles (1795-97, II, p. 196).

${ }^{76}$ El mantenimiento de un ciclo cerrado en la energía y los nutrientes es una de las claves de la agricultura preindustrial. Al respecto, v. las sugerencias de Foster y Magdoff (2000).

${ }_{77}$ Recordemos las palabras de Cavanilles sobre la escasez de abonos en la Baronía de Planes -v. supra-, donde los labradores se veían obligados a utilizar los recursos que les proporcionaba el bosque -básicamente matojos- como abono.

${ }^{78}$ Sin Alcoi, y haciendo una estimación prudente -coeficiente 5 para la conversión de vecinos del censo de 1510 - la población podía haberse multiplicado por cuatro entre 1510 y 1786 -de unos 10.000 habitantes a unos 38.000. Para las cifras de población, v. Torró Gil (2000, pp. 53-70).

${ }^{79}$ De hecho, en la segunda mitad del siglo XIX seguía practicándose este tipo de rotación en el secano. La única, aunque importante, diferencia es que cada hoja daba al año dos cosechas, una de trigo y otra de maíz. Véase Tonda (1989, p. 152).

${ }^{80}$ Donde la escasa calidad del suelo susceptible de ser regado obligaba periódicamente a traer tierra de otras partes del término municipal. Cavanilles (1795-97, II, p. 166).
} 


\section{CONCLUSIÓN}

Así pues, y en la medida en que este ejemplo local sea válido, las transformaciones que conoció el campo valenciano a lo largo de la Edad Moderna fueron importantes y de una profunda significación. Por un lado, es necesario señalar que, a simple vista, los cambios más llamativos residen en el creciente grado de comercialización de la producción y la consiguiente tendencia a la extensión e integración de los mercados. Ahora bien, desde mi punto de vista este proceso no es independiente de los cambios ocurridos en la esfera de la producción. La estructura agraria en Alcoi se caracterizó por una acusada tendencia a la concentración de la propiedad de la tierra y a una asalarización de las relaciones de producción relativamente importante ${ }^{81}$. Del mismo modo, existen indicios que hacen sospechar que, en una gradación que dependería, entre otras cosas, del volumen de población, el resto de la comarca también habría sufrido procesos similares ${ }^{82}$.

La doble tendencia observada a la especialización y a la diversificación, por otro lado, supuso la construcción de una agricultura que, en buena medida, superaba las limitaciones técnicas y organizativas de los sistemas agrarios característicos del feudalismo. Ahora bien, a pesar de sus indudables progresos, también supuso probablemente, en el muy largo plazo y ciñéndonos exclusivamente al ámbito de la producción cerealícola, una pérdida neta en la eficiencia energética de la agricultura de la zona. Si los datos manejados son correctos, el contenido energético de los cereales producidos en Alcoi podría haber disminuido en un 2,74 por cien por unidad entre 1616-27 y 180783. Dada la mayor intensidad en abonos y trabajo necesaria para lograr el incremento de los rendimientos, parece lógico suponer que el balance energético final se deterioró en una proporción considerablemente mayor, aunque sea imposible por el momento realizar ninguna estimación aproximada.

${ }^{81}$ La tendencia a la concentración de la propiedad es observable desde el mismo momento de la conquista feudal -v. Torró Abad (1992, pp. 207-232)-, y se encontraba muy avanzada a principios del siglo XVII -Torró Gil (2000, p. 162). En 1784, sólo 410 contribuyentes de un total de 2.693 -apenas un 15 por cien- eran propietarios de tierras -Aracil, y Garcia Bonafé (1974, pp. 67-85). A principios del siglo XIX (1807), cuando la población activa agraria ya sólo representaba el 35 por cien del total, sólo el 20 por cien de los activos agrarios cultivaban tierras propias, el 32 por cien tierras ajenas -probablemente de forma mayoritaria en régimen de aparcería- y el restante 48 por cien serían asalariados. Torró Gil (2000, pp. 178-179).

${ }^{82}$ Torró Gil (2000, pp. 178-179).

${ }^{83}$ El cálculo parte de las equivalencias en kcal/kg que ofrecen Campos y Naredo (1980) -dado que utilizan ejemplos históricos- y de los datos estimados por mí mismo en Torró Gil (2000, p. 193). He de hacer notar que Campos y Naredo no ofrecían equivalencias para el centeno y la avena, que han sido obtenidas de Mataix y Mañas (1998). A pesar de que las equivalencias varían considerablemente de unas fuentes a otras, en este caso el escaso peso de la avena y el centeno hacen que esto no pueda influir decisivamente en el resultado final. 
Aunque de forma lenta y acumulativa, el proceso que se ha descrito no supuso una sustitución de unos cultivos por otros sin más. Implicaba, también, cambios de gran importancia. Tras la aparente estabilidad de procedimientos y aperos, se oculta en realidad el desarrollo de otros que, sin alterar radicalmente la base técnica, representaban transformaciones profundas en la agricultura ${ }^{84}$. El resultado, visto en el largo plazo, tuvo una dimensión difícil de menospreciar. Como ocurrió en otras agriculturas en principio más avanzadas, las transformaciones se basaron en la introducción de nuevos cultígenos y nuevas rotaciones, la dedicación específica a determinados cultivos y el abandono o la relegación de otros, un uso más intensivo de los recursos que se hallaban a disposición de los agricultores, y la superación de determinados condicionantes ambientales como la escasez de abonos o de riego ${ }^{85}$. De esta manera se pudo dar un incremento en la oferta de bienes agrarios sin un deterioro dramático de la productividad del trabajo y, consiguientemente, sin que el alza de los precios estrangulase el crecimiento. A pesar del incremento de los precios locales a finales del siglo XVIII, en la primera década del siglo XIX, con una población que, según las medias de los bautismos, podía haber aumentado desde el período de $1621-30$ un 187,16 por $\operatorname{cien}^{86}$, y con una producción en crecimiento, el nivel de precios era apenas un 34,58 por cien superior. Si la comparación se efectúa entre mediados del siglo XVII y mediados del XVIII, el resultado es aún más impactante: desde la década de 1650 hasta la de 1760 el crecimiento de la población se cifraría en un 127,51 por cien, mientras que los precios habrían bajado un 29,69 por cien -Torró Gil (2000, pp. 218-219). En el caso que nos ocupa, ello puso las condiciones para la transferencia de población activa desde el sector agrario al industrial. La industrialización de la pañería alcoyana se vio favorecida, sin lugar a dudas, por ello ${ }^{87}$.

${ }^{84}$ En este sentido, hay que tener presentes las incisivas reflexiones de François Sigaut (2004) sobre la evolución técnica de la agricultura feudal. Según este autor, aunque los elementos técnicos básicos de la agricultura mediterránea estaban ya configurados hacia finales de la Antigüedad clásica, los cambios que se sucedieron con posterioridad distan mucho de ser desdeñables, y se encuentran vinculados a condicionantes ambientales de primera magnitud. Destacan especialmente sus sugerencias respecto a los aperos -especialmente referidos al arado y a los instrumentos de siega- y a las rotaciones de cereales.

${ }^{85}$ Incluso en este último extremo, las diferencias con las agriculturas del norte de Europa son menos acusadas de lo que puede parecer inicialmente. Por poner un ejemplo, en determinadas zonas de Inglaterra el principal problema técnico que se presentaba era el drenaje de unas tierras con exceso de agua -Allen (2002, p. 20)-; en nuestro caso, evidentemente, el problema era justo el contrario. En el caso español, las explicaciones sobre los problemas agrarios en la Edad Moderna van adquiriendo progresivamente mayor complejidad a la luz de los avances en la investigación. Véase, p.e., la notable aportación de Enrique Llopis (2004), esp. pp. 28-39.

${ }^{86}$ Se trata de una serie de bautismos que comprende doce parroquias de la comarca alcoyana y en la que no se incluyen datos de Alcoi -con lo que los datos se encuentran sesgados a la baja. Vid. Torró Gil (2000, p. 62).

${ }^{87}$ V. Torró Gil (2000). 


\section{BIBLIOGRAFÍA}

Alberola RomÀ, A. (1984): Jurisdicción y propiedad de la tierra en Alicante (ss. XVII y XVIII). Alacant: Ajuntament/Universitat.

AlLEN, R. C. (2002): «Revolución en los campos: La reintepretación de la Revolución Agrícola inglesa». Historia Agraria 26, pp. 13-32.

Anes Álvarez, G. (1970): Las crisis agrarias en la España Moderna. Madrid: Taurus.

Aracil, R. y García Bonafé, M. (1974): Industrialització al País Valencià (el cas d'Alcoi). Valencia: Eliseu Climent editor.

- (1974): «Els inicis de la industrialització a Alcoi». Recerques no 3, pp. 23-45.

Ardit LucAs, M. (1987): «Expulsió dels moriscos i creixement agrari al País Valencià». Afers 5-6, pp. 273-316.

- (1992): Agricultura y crecimiento económico en la Europa occidental moderna. Madrid: Síntesis.

- (1993): Els homes i la terra del País Valencià. Barcelona: Curial, dos vóls..

- (1996): "Agricultura e industria rural en el siglo XVIII», en J. Azagra, E. Mateu y J. Vidal (eds.), De la sociedad tradicional a la economía moderna. Estudios de historia valenciana contemporánea. Alacant: Instituto de Cultura «Juan Gil-Albert».

- (2004): Creixement econòmic i conflicte social. La foia de Llombai entre els segles XIII i XIX. Catarroja-Barcelona: Editorial Afers.

Aymard, M. (1983): «Autoconsommation et marchés: Chayanov, Labrousse ou Le Roy Ladurie?». Annales. E.S.C. 38 (6), pp. 1.392-1.409.

Badenes Martín, M. A. y Bernat Martí, J. S. (1994): Crecimiento de la población valenciana (1609-1857). Valencia: Alfons el Magnànim.

Beramendi y Freyre, C. (1994): El País Valenciano a fines del siglo XVIII (edición a cargo de E. Soler Pascual). Alacant: Institut de Cultura «Juan Gil-Albert».

Bhaduri, A. (1998): «Eficiencia económica e instituciones agrarias». Historia agraria 15, pp. 15-25.

CAmpos, P. y Naredo, J. M. (1980): «La energía en los sistemas agrarios». Agricultura y Sociedad 15, pp. 17-113.

CASEY, J. (1981): El regne de València al segle XVII. Barcelona: Curial.

Cavanilles, A. J. (1795-97): Observaciones sobre la Historia Natural, Geografia, Agricultura, Población y Frutos del Reyno de Valencia. Madrid, 2 vols. (edición facsímil).

Cомет, G. (1992): Le paysan et son outil. Essai d'histoire des céréales (France, VIII ${ }^{e}-X V^{e}$ siècle). Roma: École Française de Rome.

Foster, J. B. y Magdoff, F. (2000) : «Liebig, Marx and the depletion of soil fertility: relevance for today's agriculture», en F. Magdoff, J. B. Foster y F. Buttel, Hungry for Profit. The Agribussiness Threat to Farmers, Food, and the Environment. Nueva York : Monthly Review Press, pp. 43-60.

Furió Diego, A. (1982): Camperols del País Valencià. Sueca una comunitat rural a la tardor de l'Edat Mitjana. Valencia: Alfons el Magnànim.

García CÁrCel, R. (1976): «El censo de 1510 y la población valenciana del siglo XVI». Cuadernos de Geografía 18, pp. 49-66.

García Sanz, A. (1986): Desarrollo y crisis del Antiguo Régimen en Castilla la Vieja. Economía y sociedad en tierras de Segovia de 1500 a 1914. Madrid: Akal. 
Garrabou, R. (1985): Un fals dilema. Modernitat o endarreriment de la agricultura valenciana (1850-1900). Valencia: Alfons el Magnànim.

Gullickson, G. (1983): «Agriculture and Cottage Industry: Redefining the Causes of ProtoIndustrialization». The Journal of Economic History XLIII, pp. 831-850

Kriedte, P., Medick, H. y Schlumbohm, J. (1986): Industrialización antes de la industrialización. Barcelona: Crítica.

Le Roy Ladurie, E. (1969): Les paysans du Languedoc. París: Flammarion.

Llopis Agelán, E. (2004): «España, la 'revolución de los modernistas’ y el legado del Antiguo Régimen», en E. Llopis (ed.), El legado del Antiguo Régimen en España. Barcelona: Crítica, pp. 11-76.

Marcos Martín, A. (2000): España en los siglos XVI, XVII y XVIII. Economía y sociedad. Barcelona: Crítica/Caja Duero.

Mataix, J. y Mañas, M. (1998): Tabla de composición de alimentos españoles. Granada: Universidad de Granada.

Mateu ToRtosa, E. (1987): Arroz y paludismo. Riqueza y conflictos en la sociedad valenciana del siglo XVIII. Valencia: Alfons el Magnànim.

Mendels, F. J. (1972): «Proto-industrialization: the First Phase of Industrialization Process». The Journal of Economic History XXXII (2), pp. 241-261.

Nebot Cerdà, J.R. (1993): «El Medi Físic», en J. R. Nebot, J. Torró Abad, C. M. Mansanet y A. Martínez, L’Alcoià i el Comtat, guia natural, històrica i cultural. Alcoi: Joyería y Relojería Nebot, pp. 25-46.

PaLop Ramos, J. M. (1982): «El producto diezmal valenciano durante los siglos XVII y XVIII», en J. Goy y E. Le Roy Ladurie, Prestations paysannes, dîmes, rente foncière et mouvement de la production agricole à l'époque préindustrielle. París: Mouton, pp. 407-416.

Piqueras Haba, J. (1981): La vid y el vino en el País Valenciano (Geografía económica: 1564-1980). Valencia: Institució Alfons el Magnànim.

Peris Albentosa, T. (1995): «La evolución de la agricultura valenciana entre los siglos XV y XIX: rasgos cualitativos y problemas de cuantificación». Revista de Historia Económica XII (3), pp. 473-508.

- (2003): La terra de l'arròs i les moreres. Història de la Ribera. De vespres de les Germanies fins a la crisi de l'Antic Règim (segles XVI-XVIII). Volum II. Alzira: Edicions Bromera.

Pla Alberola, P. J. (1991): «Despoblación y repoblación. La crisis del XVII en el Cuartel de La Marina y Las Montañas», en J. Nadal Oller, La evolución demográfica bajo los Austrias. Alacant: I.C. «Juan Gil-Albert»-Seminari d’Estudis sobre la Població del País Valencià.

Rist, G. (1996): Le développement. Histoire d'une croyance occidentale. París: Presses de la Fondation Nationale de Sciences Politiques.

SERRANO JAÉN, J. (1993): «Desenvolupament i destrucció d'una minoria: els moriscos al senyoriu d'Elx». Recerques 27, pp. 53-72.

Sigaut, F. (2004): «L'évolution des techniques», en M. Barceló y F. Sigaut (eds.), The making of feudal agricultures?. Leiden-Boston: Brill, pp. 1-31.

Tello Aragay, E. (1995): Cervera i la Segarra al segle XVIII. En els orígens d'una Catalunya pobra, 1700-1860. Lleida: Pagès.

Tonda Monllor, E. M. (1989): «Notes sobre l'estructura agrària i dels conreus a Alcoi a les darreries del segle XIX» en VV.AA., Actes del Congrés d'Estudis de l'Alcoià-Comtat. Alcoi: Associació Cultural Alcoià-Comtat- Institut de Cultura «Juan Gil-Albert», pp. 147-158. 
Torras ElíAs, J. (1993): «La construcció del mercat», en VV.AA, Els espais del mercat. II Col-loqui internacional d'història local. Valencia: Diputació Províncial.

ToRRó ABAD, J. (1989): «Sobre ordenament feudal del territori i trasbalsaments de la població mudèjar. La Montanea Valencie (1286-1291)». Afers 7, pp. 95-124.

- (1992): La formació d’un espai feudal. Alcoi de 1245 a 1305. Valencia: Diputació de València.

- (1999): El naixement d'una colònia. Dominació i resistència a la frontera valenciana (1238-1276). Valencia: Publicacions de la Universitat de València.

Torró GiL, L. (1994): Abans de la indústria. Alcoi als inicis del sis-cents. Alacant : Universitat d'Alacant.

- (2000): «Proto-indústria i acumulació originària de capìtal a la vila valenciana d’Alcoi (1430-1823)». Universitat d'Alacant, Tesis doctoral inédita, 2 vols.

Yun Casalilla, B. (1987): Sobre la transición al capitalismo en Castilla. Economía y sociedad en Tierra de Campos (1500-1830). Salamanca: Junta de Castilla y León. 


\section{APÉNDICE}

\section{PRODUCCIÓN Y CONSUMO DE BIENES AGRARIOS EN ALCOI SEGÚN PÉREZ PLANELLES (1807)}

\begin{tabular}{|c|c|c|c|c|c|}
\hline Producto & \begin{tabular}{|c|}
$\begin{array}{c}\text { Producción } \\
\text { local }^{1}\end{array}$ \\
\end{tabular} & Precio & Consumo $^{1}$ & Saldo $^{1}$ & Procedencia \\
\hline Trigo & $6.973,5$ & 180 & $\begin{array}{l}\text { «[...] se consumen anualmente } \\
\text { con mayor porción que se ne- } \\
\text { cesita» }\end{array}$ & & no se especifica \\
\hline Cebada & 480,0 & 90 & «[...] se consumen $[\ldots] »$ & & \\
\hline Centeno & 74,5 & 90 & $\begin{array}{l}\text { «[..] se consumen estos } \\
\text { solos, y no más [...]» }\end{array}$ & & \\
\hline Avena & 14,0 & 80 & «[...] se consumen $[\ldots] »$ & & \\
\hline Maíz & 4.000 & 120 & 5.000 & -1.000 & «[...] de fuera $[\ldots] »$ \\
\hline Garbanzos & 10,0 & 384 & $\begin{array}{l}\text { «[...] se consumen con } \\
\text { mayor porción }[\ldots . .] »\end{array}$ & & «[...] viene de fuera $[\ldots] »$ \\
\hline Alubias & 100,0 & 480 & 150 & -50 & «[...] viene de fuera $[\ldots] »$ \\
\hline Lentejas & 40,0 & 270 & «[...] se consumen $[\ldots] »$ & & \\
\hline Guijas & 3,0 & 180 & «[...] se consumen $[\ldots] »$ & & \\
\hline Nabos & 50,0 & 6 & 600 & -550 & $\begin{array}{l}\text { «[...] vienen de los pue- } \\
\text { blos comarcanos }[\ldots] »\end{array}$ \\
\hline $\begin{array}{l}\text { Pimientos, } \\
\text { habas y } \\
\text { guisantes }\end{array}$ & 50,0 & 6 & 3.000 & - 2,950 & no se especifica \\
\hline $\begin{array}{l}\text { Calabazas, } \\
\text { melones, } \\
\text { sandías }\end{array}$ & $1.000,0$ & 6 & 12.000 & -11.000 & no se especifica \\
\hline $\begin{array}{l}\text { Verduras } \\
\text { (lechuga, } \\
\text { escarola, } \\
\text { cardos } \\
\text { y otros) }\end{array}$ & 0,0 & 6 & 60.000 & -60.000 & «[...] vienen de fuera $[\ldots .] »$. \\
\hline $\begin{array}{l}\text { Fruta de } \\
\text { hueso (melo- } \\
\text { cotones, } \\
\text { ciruelos, } \\
\text { albaricoques } \\
\text { y otros) }\end{array}$ & 0,0 & 12 & 100.000 & -100.000 & $\begin{array}{l}\text { «[...]vienen de otros } \\
\text { pueblos...» }\end{array}$ \\
\hline Aceitunas & 250,0 & 12 & 500 & -250 & «[...] ha venido de fuera $[. .] »$. \\
\hline $\begin{array}{l}\text { Frutos secos } \\
\text { (almendras, } \\
\text { nueces, } \\
\text { castañas, be- } \\
\text { llotas, etc.) } \\
\end{array}$ & 0,0 & 180 & 100 & -100 & no se especifica \\
\hline \begin{tabular}{l|} 
Fruta de \\
pepita (peras, \\
manzanas, \\
granadas, \\
nísperos, etc.)
\end{tabular} & 0,0 & 10 & 70.000 & -70.000 & no se especifica \\
\hline Naranjas & 0,0 & 9 & 50.000 & -50.000 & no se especifica \\
\hline Limones & 0,0 & 4 & 200 & -200 & no se especifica \\
\hline Vino tinto & $67.500,0$ & $6-8$ & 100.000 & 32.500 & $\begin{array}{l}\text { «[...] de otros pueblos } \\
\text { de la comarca }[\ldots] »\end{array}$ \\
\hline Aceite & $1.000,0$ & 50 & 140.000 & -139.000 & no se especifica \\
\hline Paja & $22.000,0$ & 2 & 60.000 & -38.000 & no se especifica \\
\hline Algarrobas & 0,0 & 9 & 6.000 & -6.000 & 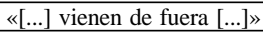 \\
\hline
\end{tabular}

Fuente: Pérez Planelles (1807, pp. 25-27)

Notas: ${ }^{1}$ El volumen de cereales, legumbres, aceitunas, frutos secos y similares, se expresa en cahíces; el del vino en cántaros. El peso del resto esta expresado en arrobas.

${ }^{2}$ Los precios son reales de vellón por cahíz, arroba o cántaro, respectivamente. 
